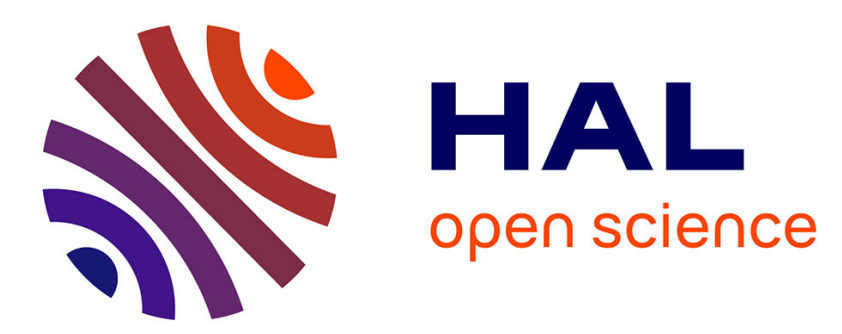

\title{
ScCO2/Green Solvents: Biphasic Promising Systems for Cleaner Chemicals Manufacturing
} Yaocihuatl Medina-Gonzalez, Séverine Camy, Jean-Stéphane Condoret

\section{To cite this version:}

Yaocihuatl Medina-Gonzalez, Séverine Camy, Jean-Stéphane Condoret. ScCO2/Green Solvents: Biphasic Promising Systems for Cleaner Chemicals Manufacturing. ACS Sustainable Chemistry \& Engineering, 2014, 2 (12), pp.2623-2636. 10.1021/sc5004314 . hal-02099765

\section{HAL Id: hal-02099765 https://hal.science/hal-02099765}

Submitted on 15 Apr 2019

HAL is a multi-disciplinary open access archive for the deposit and dissemination of scientific research documents, whether they are published or not. The documents may come from teaching and research institutions in France or abroad, or from public or private research centers.
L'archive ouverte pluridisciplinaire HAL, est destinée au dépôt et à la diffusion de documents scientifiques de niveau recherche, publiés ou non, émanant des établissements d'enseignement et de recherche français ou étrangers, des laboratoires publics ou privés. 


\section{Open Archive Toulouse Archive Ouverte (OATAO)}

OATAO is an open access repository that collects the work of Toulouse researchers and makes it freely available over the web where possible

This is an author's version published in: http://oatao.univ-toulouse.fr/23707

Official URL: https://doi.org/10.1021/sc5004314

\section{To cite this version:}

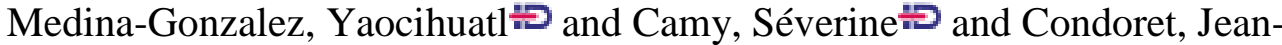
Stéphane Chemicals Manufacturing. (2014) ACS Sustainable Chemistry \& Engineering, 2 (12). 2623-2636. ISSN 2168-0485

Any correspondence concerning this service should be sent to the repository administrator: tech-oatao@listes-diff.inp-toulouse.fr 


\title{
$\mathrm{ScCO}_{2} /$ Green Solvents: Biphasic Promising Systems for Cleaner Chemicals Manufacturing
}

\author{
Yaocihuatl Medina-Gonzalez, ${ }^{*},+\neq$ Séverine Camy, ${ }^{\dagger, \ddagger}$ and Jean-Stéphane Condoret ${ }^{\dagger, \ddagger}$ \\ ${ }^{\dagger}$ CNRS, LGC (Laboratoire de Génie Chimique), 4, allée Emile Monso, BP 84234, 31030 Toulouse Cedex 4, France \\ ‡Université de Toulouse, UPS, INSA, INPT, LGC (Laboratoire de Génie Chimique), F-31077 Toulouse, France
}

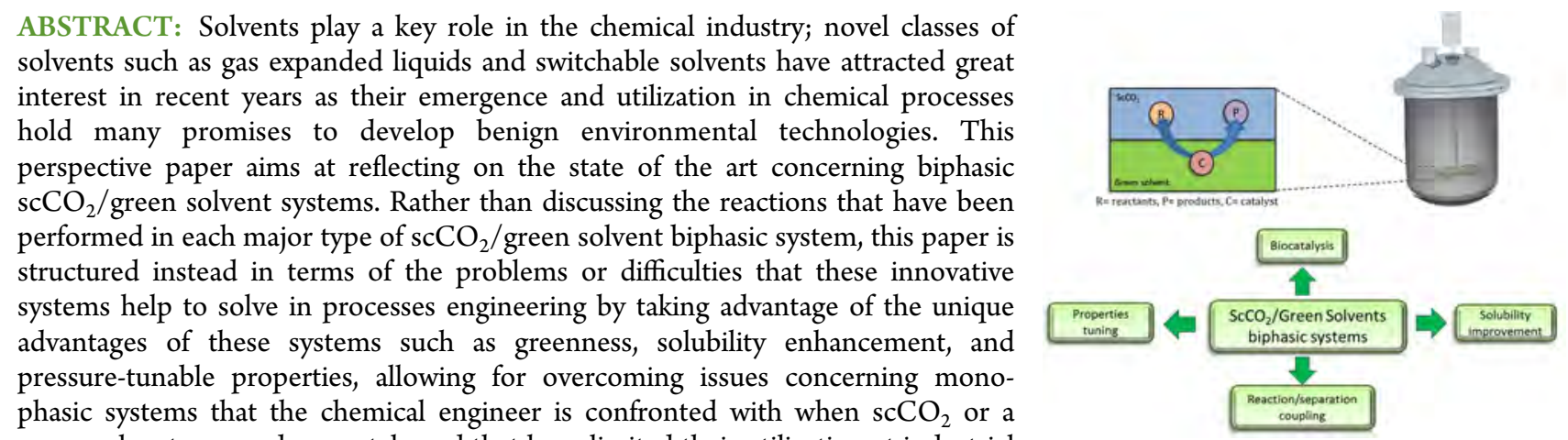
green solvent are used separately and that have limited their utilization at industrial scales. Among such issues, one can cite (1) difficulties in the solubilization of these compounds, (2) difficult separation of reactants, products, and catalysts, and (3) loss of the catalyst. These problems arise on one hand from the poor solvent power of $\mathrm{scCO}_{2}$ when used in homogeneous phase and on another hand from the need for a decrease in the usage of distillation as a separation technique. However, their association in biphasic systems allows for overcoming these problems and provides unique opportunities and perspectives to develop future versatile, flexible, and atom economical chemical processes in full accordance with the principles of green sustainable engineering. The green solvents considered in this perspective paper are water, ionic liquids, biobased ionic liquids, and other green solvents such as glycerol and liquid polymers. Ionic liquids have been considered in this paper as they have been claimed as "green" because they allow the prevention of volatile emissions; however, some of them present toxic issues together with a high environmental impact because of their nonbiodegradability and high manufacturing costs. ${ }^{1} \mathrm{We}$ have then tried to attract special attention to biosourced ionic liquids that may have better toxicological and environmental properties and that may hold promise for their future use in chemical processes. This paper presents also the studies concerning phase equilibrium between $\mathrm{scCO}_{2}$ and green solvents where biphasic systems can be obtained, as phase behavior control is an interesting tool for designing effective catalytic reactions and catalyst-product separation processes. The unique properties of green solvents that have been proposed as a homogeneous phase in previous studies have prompted us to include them in this perspective paper with the aim of interesting the scientific community in testing them in biphasic systems including $\mathrm{scCO}_{2}$. Finally, some reflections about the next steps toward greener processes using $\mathrm{scCO}_{2} /$ green solvent biphasic systems are presented and concern technical and scientific requirements to take full advantage of the capabilities of these systems.This perspective paper does not intend to be comprehensive but instead tries to attract attention on recent usages of these systems in order to stimulate future advances in the study and development of such systems.

KEYWORDS: Supercritical $\mathrm{CO}_{2}$ Biphasic systems, Green solvents, Green sustainable engineering

\section{INTRODUCTION}

What Is a Green Solvent? In the search for new alternatives for traditional solvents, one is quickly confronted with the question "what is a green solvent?" It is generally accepted that the definition of green solvents is not an easy task. A solvent can be biodegradable but be volatile and ozone depleting. It can have an extremely low impact on health and the environment but needs a great amount of energy to be manufactured, etc. As it has been accurately pointed out by Jessop et al., ${ }^{2}$ several questions must be answered before deciding that a solvent is greener than other solvents. In the same way for a process to be both green and sustainable, it must address both environmental and economic considerations. ${ }^{3}$ Nevertheless, it is generally accepted that low impact on health and the environment as well as low volatilities are desirable characteristics of green solvents. However, even if low volatility is a highly desirable characteristic in a solvent, several solvents considered as "green" such as ethanol, ethyl acetate, and limonene are volatile yet at the same time are greener than other less volatile solvents. 
As things stand currently, the low volatilities of most of the green solvents make their industrial implementation difficult for the simple reason that they are hardly distilled. In fact, in industry, distillation is the most used separation method to remove solvents from products. This technique demands great quantities of energy and requires the solvent to be volatile; indeed, the contribution of distillation to overall emissions of volatile organic compounds (VOCs) to the atmosphere is large. As can be easily understood, the principal difficulty in nonvolatile greener solvent implementation is the dependence of industry on distillation for solvent separation, ${ }^{2,4}$ and future utilization of greener solvents will pass through the development of new processes, innovative equipment, and creative strategies allowing for low cost and easy separation of nonvolatile solvents. These are some of the challenges in green sustainable engineering: integrating sustainability and greenness as inherent components of engineering design. ${ }^{3}$ This perspective paper will focus on green solvents as these compounds may form biphasic mixtures with $\mathrm{CO}_{2}$ over a large range of temperatures and pressures, and, as will be presented, $\mathrm{scCO}_{2} /$ green solvent biphasic systems can help to implement greener low volatile solvents in industry by responding, among others, to this separation issue.

$\mathrm{ScCO}_{2}$ in Biphasic Systems Helps To Implement Green Solvents in Industry. Supercritical $\mathrm{CO}_{2}\left(\mathrm{scCO}_{2}\right)$ has attracted great attention in recent years as an alternative solvent because of its greenness, lack of reactivity, good transport properties, zero surface tension, high diffusivity, and abundance as $\mathrm{CO}_{2}$ is a major industrial waste. ${ }^{5,6}$ According to the International Energy Agency, the $\mathrm{CO}_{2}$ global emissions increased by $1.3 \mathrm{GtCO}_{2}$ between 2009 and 2010, and in 2010, the emission of $\mathrm{CO}_{2}$ from fuel combustion reached 30.3 $\mathrm{GtCO}_{2}{ }^{7}$, while the total amount of carbon dioxide used in industry is approximately $120 \mathrm{MtCO}_{2}$ per year. $^{8}$

$\mathrm{ScCO}_{2}$ presents physicochemical properties that are highly desirable for a solvent. Diffusion coefficients of solutes are higher in $\mathrm{scCO}_{2}$, and viscosities of these mixtures are lower than when traditional solvents are used. One interesting advantage of $\mathrm{scCO}_{2}$ is its complete miscibility with gases, while the solubility of liquids and solids in $\mathrm{scCO}_{2}$ is strongly dependent on $\mathrm{CO}_{2}$ density, which allows an easy separation of dissolved reactants, products, and catalysts by simple temperature and pressure changes. The use of $\mathrm{scCO}_{2}$ as a solvent has the advantage of its easy separation by depressurization and its easy recompression and recycling. These properties have increased the incentive to use $\mathrm{scCO}_{2}$ as an alternative solvent in the extraction of caffeine, aroma, and active compounds ${ }^{9-14}$ and as reaction medium for reactions such as oxidations, ${ }^{15-17}$ alkylations, ${ }^{18}$ etherifications, ${ }^{19}$ hydroformylations, ${ }^{20}$ and hydrogenations $^{21}$ among others. However, even though the utilization of $\mathrm{scCO}_{2}$ at an industrial scale in the food and aroma industries is well established, only very few examples of industrial chemical production have been developed ${ }^{22}$ even if several lab-scale studies have been reported.

From an environmental point of view, the most interesting feature of the use of $\mathrm{scCO}_{2}$ as a solvent is that it can be easily recovered at the end of the process, recompressed, and recycled. However, despite all these interesting characteristics, $\mathrm{scCO}_{2}$ presents a drawback that limits its utilization at industrial and research scales when used as a homogeneous phase; given its low polarity, $\mathrm{scCO}_{2}$ barely dissolves polar organic compounds and currently used catalysts, which reduces its suitability as a solvent in industrially used reactions, specially those using transition metal complexes as catalysts. ${ }^{23-25}$

Some strategies have been developed to improve the solvent power of $\mathrm{scCO}_{2}$. In particular, to solubilize catalysts, the most intuitive is to use a cosolvent, which is typically added at $1-2 \%$ mass to improve the solubility of compounds that are poorly soluble in pure $\mathrm{scCO}_{2}$. When the volume of the cosolvent increases to $20-50 \%$ in volume, the cosolvent may become another phase, and the system becomes biphasic. If $\mathrm{CO}_{2}$ dissolves in this phase and this phase expands as a product of $\mathrm{CO}_{2}$ dissolution, it is called a gas-expanded liquid (GXL) or a $\mathrm{CO}_{2}$-expanded liquid ( $\left.\mathrm{CXL}\right){ }^{26}$ This resulting phase presents enhanced transport properties that have been used for difficult extractions and antisolvent processes ${ }^{27}$ and in reactions such as oxidations, hydrogenations, epoxidations, hydroformylations, etc. $^{23,28,29}$ As has been pertinently stated by P. G. Jessop and B. Subramaniam, ${ }^{26}$ CXLs combine the advantages of compressed $\mathrm{CO}_{2}$ and of traditional solvents in an optimal manner that enhances transport properties by increasing diffusivity and by decreasing the viscosity of the partner solvent, while this partner solvent keeps the solubility power of the system. One of the principal advantages of such systems is the possibility to tune the solubility and physicochemical properties of the mixture in a range from the properties of the conventional solvent to those of pure $\mathrm{scCO}_{2}$ in a reversible way by controlling the concentration of $\mathrm{CO}_{2} \cdot{ }^{30}$ As examples, the viscosity of $\mathrm{CO}_{2}$-expanded methanol decreases by nearly $80 \%$ with 77 bar of $\mathrm{CO}_{2}$ compared to pure methanol; ${ }^{31}$ reduction of viscosity of ionic liquids is even more dramatic in the presence of pressurized $\mathrm{CO}_{2} \cdot{ }^{32,33}$ Physicochemical and solubility properties of mixtures containing $\mathrm{CO}_{2}$ can then be easily controlled by small changes in pressure, triggering immiscibility of compounds in $\mathrm{scCO}_{2}$ and giving the key for tuning separations and reactions. ${ }^{34}$ A review published by B. Subramaniam ${ }^{35}$ presents the state of the art concerning conventional organic solvents expanded by $\mathrm{CO}_{2}$ and their applications in catalysis and novel materials. So, $\mathrm{scCO}_{2}$ coupled to a solvent can be used as a biphasic catalytic system, in which the catalyst is dissolved in the so-called reactional phase, composed of solvent and of dissolved $\mathrm{CO}_{2}$. The second phase, being nonreactional and mainly $\mathrm{scCO}_{2}$, represents a reservoir for reactants and/or products that can be separated easily, enabling easy reuse of the catalytic phase (Figure 1). ${ }^{36,37}$

Biphasic catalysis is not a new process. Some remarkable examples of the power of biphasic catalytic systems are the Shell higher olefin process (SHOP) that was the first commercial process based in a biphasic butanediol/hydrocarbon system for the production of alfa olefins from ethylene using a nickel-based catalyst. ${ }^{38}$ Another example is the Ruhrchemie/Rhône Poulenc process for the hydroformylation of propylene to butyraldehyde that is performed with a watersoluble $\mathrm{Rh}$ catalyst in an aqueous biphasic system that fabricates around 600000 tons/year of products. ${ }^{39}$ These industrially important processes demonstrate the capabilities of biphasic systems and suggest that biphasic $\mathrm{scCO}_{2}$ /green solvents may take an important place in forthcoming years as substitution for current processes and/or as tools to develop innovative chemical processes.

However, even if CXLs represent a step forward in the development of greener processes, they have mostly included conventional organic volatile solvents, which do not solve entirely the environmental issue of toxic volatile solvent usage and wastage. From our point of view, usage of green solvents 


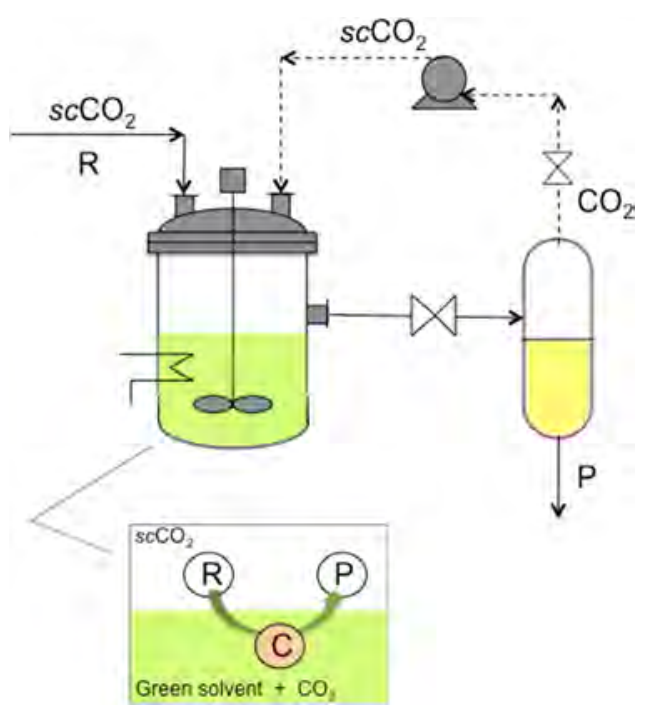

Figure 1. General schema showing a $\mathrm{scCO}_{2} /$ green solvent biphasic reactional system with $\mathrm{R}=$ reactants, $\mathrm{P}=$ products, and $\mathrm{C}=$ catalyst.

instead of traditional organic solvents will be absolutely necessary in the development of next-generation chemical processes. In particular, usage of biosourced solvents and/or solvents that are manufactured from fully renewable resources, are biodegradable, and are less harmful than traditional solvents ${ }^{40}$ will present in addition a wide range from where one can choose nonVOCs biosourced solvents. In this way, the entire process can become greener. A review has been recently published by $\mathrm{Y}$. Gu and F. Jérôme concerning the design of biosourced solvents and their utilization in catalysis and organic chemistry; ${ }^{41}$ interested readers are encouraged to refer to it.

Thus, promising advantages that $\mathrm{scCO}_{2} /$ green solvent biphasic media may offer include the following: (1) Products can be separated by depressurization. (2) The catalyst is retained in the so-called reactive phase allowing its reutilization. (3) $\mathrm{scCO}_{2}$ allows tuning properties of the green solvent in the same fashion as in CXLs. (4) Nonvolatile solvents can be used, such as some biosourced solvents. In this manner, biphasic $\mathrm{scCO}_{2}$ /green solvents can then help not only to solve green chemistry and engineering challenges but also to create innovative flexible processes.

This perspective paper aims to reflect the state of the art concerning $\mathrm{scCO}_{2}$ /green solvent biphasic systems, as from our point of view, the use of these systems at research and industrial scales would represent a step forward in the development of greener processes. Although there is growing publication activity combining these interesting systems, as shown in Figure 2, the number of reports is still modest. However, the number of publications and patents is expected to grow as $\mathrm{scCO}_{2}$ and green solvents are gaining an important place in research and development.

$\mathrm{ScCO}_{2} /$ Green Solvent Biphasic Systems To Solve Solubility Issues in Industry. Some examples of current industrial catalytic processes that present challenges regarding sustainability and greenness are the homogeneous hydroformylation of higher olefins, selective oxidation of light olefins such as ethylene and propylene, and production of terephthalic acid by oxidation of $p$-xylene. ${ }^{27}$ Hydroformylation of higher olefins is used to obtain oxygenated hydrocarbon compounds from olefinic petrochemicals; the products thus obtained can then be used as building blocks in the chemical and

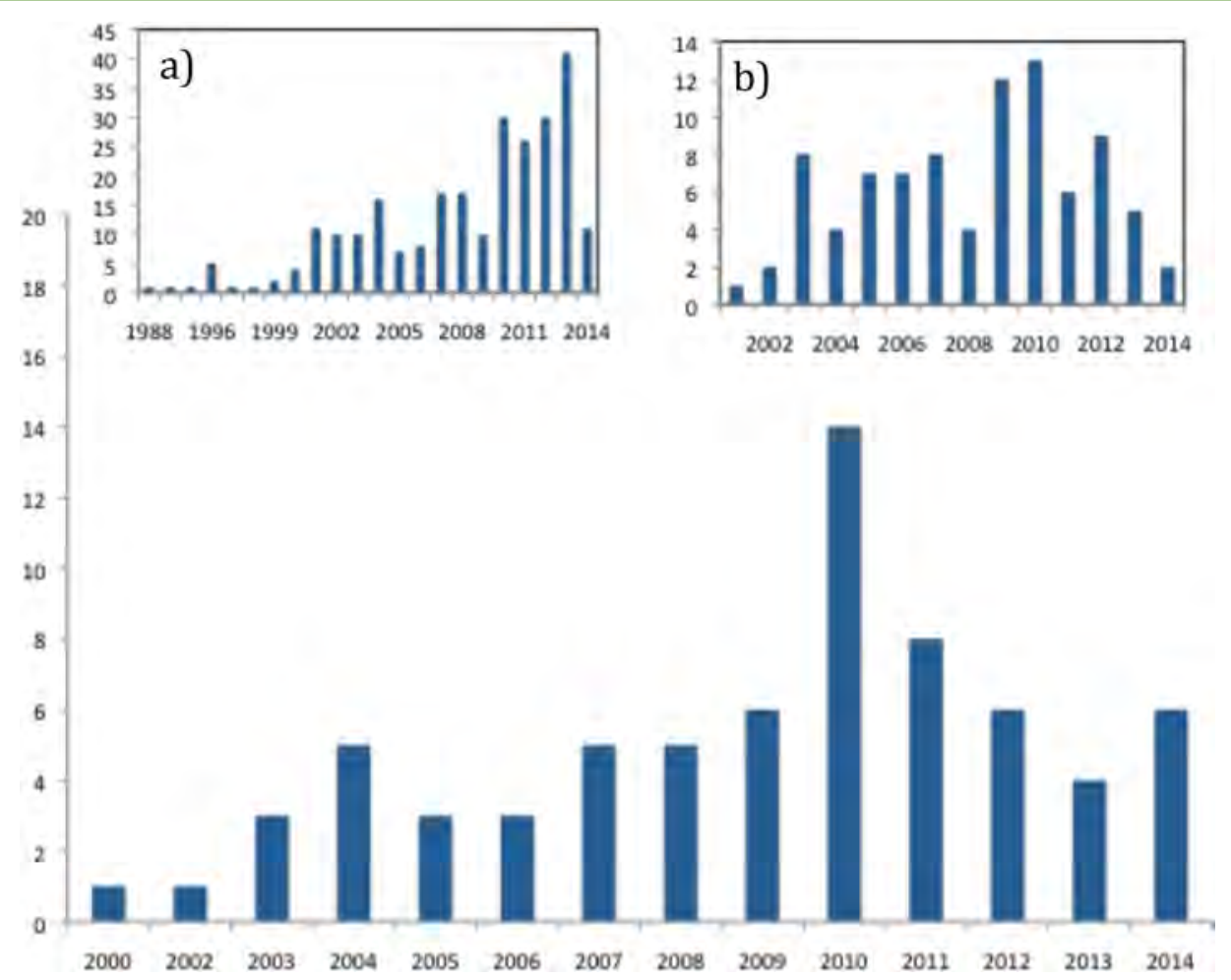

Figure 2. Annual number of scientific publications and patents since 1995. Data analysis completed using the SciFinder search system on April 17, 2014 , and using the search terms "scCO2" and/or "supercritical $\mathrm{CO}_{2}$ " and "green solvents". Insets represent results obtained by using (a) "scCO2" and "water" and (b) "scCO2" and "ionic liquids". 
pharmaceutical industries. Industrial hydroformylation processes suffer from the limited solubilization of gaseous reactants $\left(\mathrm{H}_{2}\right.$ and $\left.\mathrm{CO}\right)$ in the liquid reaction phase and the need for efficient and eco-compatible catalyst recovery and recycling, as this last operation needs great quantities of solvents, acids, and bases. Oxidations of light olefins performed in a homogeneous liquid phase suffer from the low solubility of $\mathrm{O}_{2}$ in liquids that leads to $\mathrm{O}_{2}$ starvation and a decrease in reaction rate and selectivity. Scientific and technological responses are then needed to overcome these challenges.

It is not surprising that the first investigated applications of biphasic systems including $\mathrm{scCO}_{2}$ involved other gases such as $\mathrm{H}_{2}$ and $\mathrm{O}_{2}$, as they are soluble in all proportions in this solvent. As discussed in the next paragraphs, oxidations and hydrogenations using molecular oxygen and hydrogen have taken advantage of the solubility improvement of gases that $\mathrm{scCO}_{2}$ can provide when used in biphasic systems.

Some $\mathrm{scCO}_{2}$ /green solvent biphasic systems have been successfully used as responses to these and others challenges, where solubility issues are present in chemical processing. These systems will be detailed in following paragraphs.

Solubility of Gases. Several research groups have exploited the ability of $\mathrm{scCO}_{2}$ to solubilize gases and the enhanced transport properties of this solvent in systems where a gas needs to be solubilized in an immiscible or partially miscible second phase. Bhanage ${ }^{42}$ et al. have demonstrated the advantages of using a biphasic system for the hydrogenation of cinnamaldehyde in a $\mathrm{scCO}_{2} /$ water system using watersoluble $\mathrm{Ru}-$, Rh-, and Pd-based catalysts. The utilization of this biphasic system enhanced the reaction rates and selectivity to cinnamyl alcohol, compared to systems using either $\mathrm{scCO}_{2}$ or toluene as solvents, and to biphasic systems using a toluene/ water system. A $\mathrm{ScCO}_{2}$ /water system allowed easy separation of the catalyst and reactants/products as well. The enhancement in reaction rates has been attributed to the total solubility of reactant gases in $\mathrm{scCO}_{2}$, which increased the solubility of $\mathrm{H}_{2}$ in water. Up to $100 \%$ of selectivity of the saturated aldehyde was obtained when $\mathrm{RhCl}_{3}$ and $\mathrm{Pd}(\mathrm{OAc})_{2}$ were used as catalysts and up to $99 \%$ of the unsaturated alcohol when $\mathrm{RuCl}_{3}$ was used, compared to the reaction in a biphasic toluene/water system (selectivity of $8 \%$ ), and with a homogeneous operation (selectivities of $8 \%$ in toluene and $11 \%$ in $\mathrm{scCO}_{2}$ ).

Chouchi et al. ${ }^{43}$ have pointed out the same observation when $\alpha$-pinene has been hydrogenated in the presence of $\mathrm{scCO}_{2}$. In this case, $\alpha$-pinene was used as solvent and as reactant. Twophase conditions lead to increased hydrogenation rates compared to experiments without $\mathrm{CO}_{2}$, which was attributed to the higher solubility of $\mathrm{H}_{2}$ in $\alpha$-pinene induced by $\mathrm{scCO}_{2}$ than in the case of hydrogenation without $\mathrm{scCO}_{2}$. The authors used this reaction to focus the attention of the importance of the effect of phase behavior on catalytic efficiency; however, in this study, partial pressures of $\mathrm{H}_{2}$ have not been kept constant, which can be the origin of the increased yields observed in some experiments. ${ }^{43}$ In order to better understand why hydrogenations in biphasic conditions can proceed faster than in monophasic systems, Lukasik et al. ${ }^{44}$ studied the hydrogenation of limonene in a $\mathrm{scCO}_{2} /$ limonene mixture, where limonene was used as a reactant and solvent as well. The critical pressure of the mixture was below $10 \mathrm{MPa}$ allowing for switching from a monophasic to a biphasic system. Phase equilibrium was calculated using the Peng-Robinson equation of state and the Mathias-Klotz-Prausnitz mixing rule. Interestingly, it has been shown by the authors that when
$\mathrm{CO}_{2}$ is present in large excess and the system is close to the critical line of the mixture but yet being biphasic, the partition of limonene and hydrogen between the liquid and the vapor phases is quite sensitive to pressure, meaning that a small change in pressure has a big impact on the reactants ratio, allowing the tunability of the reaction rates and in particular of the selectivity of the reaction. The sometimes observed enhancing effect of $\mathrm{CO}_{2}$ pressure in hydrogenations reaction rates and enantioselectivity is controversial. J. Brennecke has found that this effect is beneficial from the $\mathrm{H}_{2}$ solubility increase with $\mathrm{CO}_{2}$ presence in acetonitrile, acetone, and methanol, ${ }^{45}$ while other authors have not found the same behavior during the synthesis of naproxene via enantioselective hydrogenation in methanol. ${ }^{46}$ In this last study, the reaction rate and enantioselectivity decreased when methanol was expanded by $\mathrm{CO}_{2}$ compared to results obtained in neat methanol. This behavior has not been attributed to $\mathrm{H}_{2}$ starvation but to the decrease in dielectric constant of methanol by the expansion with $\mathrm{CO}_{2}$.

Acetic acid has been used as solvent in a $\mathrm{scCO}_{2} /$ acetic acid system for the oxidation of $p$-xylene to terephtalic acid by employing a $\mathrm{Co} / \mathrm{Mn} / \mathrm{Br}$ catalyst. Once again, usage of such a system allowed the correct solubilization of $\mathrm{O}_{2}$ in the solvent and improved catalytic performance as the production of terephtalic acid was increased and the production of solid and gaseous byproducts was simultaneously decreased, compared to the conventional system that uses $\mathrm{N}_{2} / \mathrm{O}_{2}$ as the oxidant. This behavior was explained by a better $\mathrm{O}_{2}$ availability; even more, solvent decomposition was inhibited by the utilization of $\mathrm{scCO}_{2}{ }^{47}$

Hig -pressure biphasic mixtures of room temperature ionic liquids and $\mathrm{scCO}_{2}$ have been used for the photocatalytic reduction of $\mathrm{CO}_{2}$ to $\mathrm{CO}$ by using a [BMPYRR][TCB] IL as solvent, $\mathrm{fac}-\mathrm{ReCl}(\mathrm{bpy})(\mathrm{CO})_{3}$ as the catalyst, and triethanolamine as a sacrificial electron donor. In this study, that intended to develop artificial photosynthesis, $\mathrm{scCO}_{2}$ had the role of solvent and reactant. This system remains biphasic in a wide range of pressures and temperatures, and while $\mathrm{scCO}_{2}$ is highly soluble in ILs, these solvents are essentially not soluble in $\mathrm{scCO}_{2}$. The use of a $\mathrm{scCO}_{2} / \mathrm{IL}$ biphasic system allowed a 7folded increase in the TON (turn over number) for $\mathrm{CO}$ production at $13.4 \mathrm{MPa}$ than at atmospheric pressure. ${ }^{48}$ Prevention of the poisoning of the catalyst has been observed as well, as $\mathrm{CO}$ is more soluble in the $\mathrm{scCO}_{2}$ phase than in the IL phase avoiding a buildup of $\mathrm{CO}$ around the catalyst.

In situ generation of gaseous reactants has been illustrated by the generation of $\mathrm{H}_{2} \mathrm{O}_{2}$ from $\mathrm{H}_{2}$ and $\mathrm{O}_{2}$ in a biphasic $\mathrm{scCO}_{2}$ / water system, which has allowed for cleanly epoxidizing propylene and cyclohexene to propylene oxide (reactants previously dissolved in $\mathrm{CO}_{2}$ ) with a palladium-based catalyst, avoiding the current routes that produce high quantities of wastes and are not atom-economical. ${ }^{49-52}$

Jacobson et al. ${ }^{53}$ have reported a biphasic $\mathrm{scCO}_{2} /$ water homogeneous catalysis system using anionic and cationic surfactants to form a $\mathrm{CO}_{2}$-responsive emulsion. Hydrogenation of styrene to ethyl benzene was performed in this system by using a water-soluble rhodium-based catalyst. The solubility of hydrogen was enhanced by the use of pressurized $\mathrm{CO}_{2}$, which improved reaction rates that were found comparable to reaction rates found in homogeneous systems and superior to other water/organic solvent systems. Decreasing the pressure from 27 to $7 \mathrm{MPa}$ easily broke the emulsion, allowing efficient phase separation. Recirculation of the water-containing catalyst and its 
repressurization with $\mathrm{CO}_{2}$ permitted a repeated emulsion formation, yielding constant catalyst activity for at least three cycles.

\section{SOLUBILITY OF CATALYSTS}

Solubility of catalysts, especially complex catalysts, is a major issue in chemistry and in chemical processes engineering. In general, catalysts are soluble in polar solvents, which represents a problem when nonpolar solvents such as $\mathrm{scCO}_{2}$ are used. Some strategies have been adopted to overcome these obstacles and will be presented in following paragraphs.

$\mathrm{CO}_{2}$-Philic and/or Green Solvent-Philic Catalysts Development. Homogeneous catalysis has the advantages of presenting higher activity and selectivity than heterogeneous catalysis; however, in systems where $\mathrm{scCO}_{2}$ is used as solvent, this task is not easy as $\mathrm{CO}_{2}$ has a relatively low solvent power, especially for complex catalysts. Many previous works have focused on the design of $\mathrm{CO}_{2}$-philic catalysts, and one interesting result of these studies is that $\mathrm{CO}_{2}$ pressure can increase the solubility of fluorinated catalysts in an organic phase promoting the rate of certain reactions, while depressurization provokes catalyst precipitation, allowing it to be recycled. In these cases, $\mathrm{CO}_{2}$ acts as a solubility switch. ${ }^{54}$ This interesting feature of $\mathrm{CO}_{2}$ and its utilization for reactions such as hydrogenations and epoxidations have been reviewed in a paper published by Eckert et al. ${ }^{55}$

In order to promote green solvents such as glycerol as an alternative solvent to water when this last one cannot be used, sugar-based surfactants have been designed in order to stabilize several catalysts and are used in the ring opening of several epoxides with carboxylic acids. The surfactants thus used were aminopolysaccharides obtained by the oxidation of hydroxyethylcellulose with sodium periodate, followed by a catalytic amination over $\mathrm{Pd} / \mathrm{C}$. The catalysts obtained formed some hydrophobic environment in glycerol, and diffusion of reactants to this hydrophobic environment was possible by hydrophobic-hydrophilic interactions. ${ }^{56}$ Later on, the same authors used the same polysaccharide as a ligand for the coordination of palladium in order to obtain Pd nanoparticles with an average size of $6 \mathrm{~nm}$. These nanoparticles where used for the $\beta-\beta$ diarylation of acrylate derivatives in glycerol; the products of this reaction were efficiently extracted by $\mathrm{scCO}_{2}$ showing that a continuous operation in a biphasic system may be envisaged. ${ }^{57}$

The approach of water-in- $\mathrm{CO}_{2}$ microemulsion generation by surfactants has been used by Johnston et al. ${ }^{58}$ to create a hydrophilic environment inside $\mathrm{CO}_{2}$ and to effectively solubilize hydrophilic molecules such as proteins and ions; this environment has been characterized by spectroscopic techniques by using bovine serum albumin (BSA) as a probe.

Catalyst Immobilization. As has already been stated, homogeneous catalysis presents attractive advantages for chemical reactions such as high activity and selectivity; however, its use at industrial scale presents problems concerning catalyst recycling, product separation, and loss of the catalyst, leading to high energy consumption and waste generation. That is why heterogeneous catalysis is largely preferred in chemical processes; however, heterogenization of homogeneous catalysts by attachment to organic or inorganic supports may present some disadvantages such as loss of activity and ligand and/or metal bleeding. ${ }^{39,59}$ In biphasic reaction media, one of the phases, the so-called reactive phase, contains the dissolved catalyst, while the reaction takes place therein and products are recovered in the second phase. In this manner, the problems of catalysts recycling in homogeneous catalysis are solved; additionally, products may be easily removed if the system is carefully designed and conversion is sufficiently high, ${ }^{60}$ which may allow for reaction/separation steps coupling.

Immobilization of catalysts in a so-called reactive phase using $\mathrm{scCO}_{2} /$ green solvent biphasic systems have been extended to enzymatic reactions by taking advantage of some specificity of enzymes, such as its activity that is surprisingly maintained in ionic liquids. These concepts have been exemplified by transesterifications in $[\mathrm{BMIM}]\left[\mathrm{BF}_{4}\right]$ and $[\mathrm{BMIM}]\left[\mathrm{PF}_{6}\right]$ and in $[\mathrm{BMIM}]\left[\mathrm{Tf}_{2} \mathrm{~N}\right]$ as well as acylations in [BMIM] [BTA]; with all of them catalyzed by Candida antarctica lipase B. ${ }^{61-63}$ These biphasic systems allowed for continuous operation by using $\mathrm{scCO}_{2}$ as the extractive phase without loss of activity during up to 10 operation cycles.

$\mathrm{CO}_{2}$-Water Biphasic Systems. $\mathrm{CO}_{2} / \mathrm{H}_{2} \mathrm{O}$ biphasic systems have been used to perform the Barbier allylation of aldehydes to obtain homoallylic alcohols. This reaction is simpler that the corresponding Grignard reaction, and its industrial interest has guided several efforts to perform it in solvent-free conditions or by using ionic liquids as solvents. In the study by Cenci et al., ${ }^{64}$ the biphasic $\mathrm{CO}_{2}$ /water system has been efficiently used in the presence of ultrasound and $\mathrm{Zn}$ dust as catalyst, allowing for good selectivity (up to $100 \%$ ) and yields up to $93 \%$ in the case of allylation of benzyaldehyde by allyl bromide. In this work, the biphasic system allowed the solubilization of hydrophobic reagents by $\mathrm{CO}_{2}$; however, the inability of the reaction to progress in pure $\mathrm{CO}_{2}$ justified utilization of the $\mathrm{CO}_{2} /$ water biphasic system.

Inverted Green Solvent/scCO $\mathrm{siph}_{2}$ Biphic Systems. An inverted biphasic $\mathrm{scCO}_{2}$ /water system (Figure 3) has found

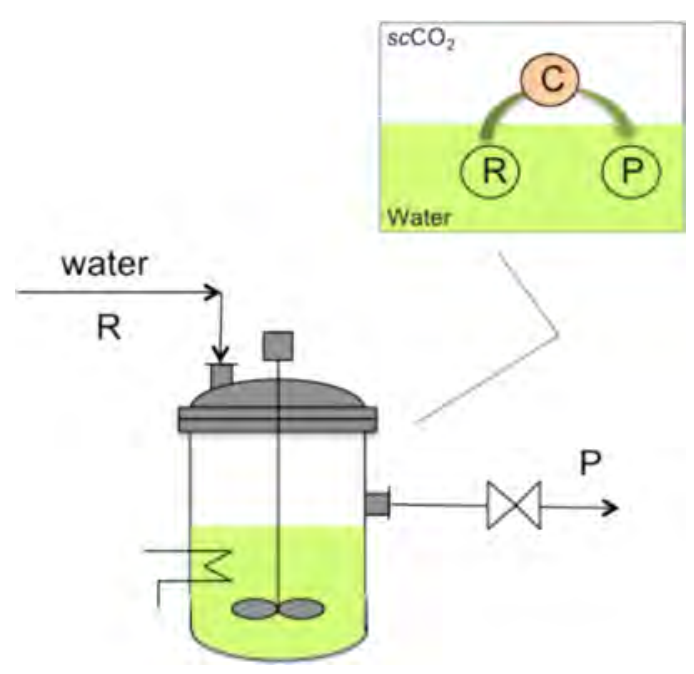

Figure 3. General schema showing an inverted $\mathrm{scCO}_{2} /$ water biphasic reactional system where $\mathrm{scCO}_{2}$ acts as a reservoir for the catalyst and water is the reactants and products carrier; $\mathrm{R}=$ reactants, $\mathrm{P}=$ products and $\mathrm{C}=$ catalyst.

interesting applications as reaction media by immobilizing the catalyst in the $\mathrm{scCO}_{2}$ phase while the organic substrate and products are carried by the aqueous phase allowing for easy separation of products from the catalyst. This general principle has been applied to the hydroformylation of water-soluble acids and to the hydrogenation of $\mathrm{C}=\mathrm{C}$ double bonds by using suitable rhodium-based $\mathrm{CO}_{2}$ soluble catalysts; ${ }^{65-67}$ even 
though the stability of the catalyst was not yet optimized, good recycling and negligible catalyst lost has been observed.

$\mathrm{ScCO}_{2} /$ Green Solvents Biphasic Systems Allow Homogeneous Catalysis and Separation Steps Coupling. Biphasic catalysis, being a powerful technique, is already applied in industry, for example, the "difasol" process, developed by the Institut Français du Pétrole to polymerize and oligomerize olefins in biphasic organic solvent/ionic liquid systems. ${ }^{68}$ Another interesting example is the hydration of butene to 2-butanol, which is performed in the presence of acid catalysts. A supercritical butene/water biphasic system is specially adapted for this application, as the solubility of butene in water is low and supercritical butene allows the separation of the product 2-butanol, shifting the reversible reaction in the forward direction. ${ }^{69}$ Supercritical fluids and GXLs have been used in recent years for multiphase catalytic reactions such as hydroformylations, hydrogenations, carbonylations, oxidations, and epoxidations by taking advantage of the tunability that these systems offer. Some reviews in this field have been published by different authors, and we encourage interested readers to refer to them. ${ }^{70}$

$\mathrm{ScCO}_{2} /$ green solvents biphasic systems have been used with the purpose of keeping homogeneous catalysis advantages coupling it to easy separation steps. The green solvents that have been used in such systems are ionic liquids, which are specially adapted to enzymatic catalysis, polyethylene glycol, water and glycerol; the use of these systems are presented in next paragraphs.

Hydrogenations, hydroformylations, and hydrovinylations are industrial reactions that have to face the challenge of low $\mathrm{H}_{2}$ solubility in liquid phases. Together with this difficulty, homogeneous catalysis of these reactions in industry presents the obstacle of separation and loss of the catalyst. Biphasic processes used to perform these reactions have allowed efficient separations of the catalyst from products. Besides, when $\mathrm{scCO}_{2}$ has been used as second phase in biphasic systems, the solubility of $\mathrm{H}_{2}$ was improved. Hydrogenations, hydroformylations, and hydrovinylations have been developed in $\mathrm{scCO}_{2} / \mathrm{IL}$ biphasic systems by using $\mathrm{scCO}_{2}$ as the carrier for reactants and products, whereas reactions took place in the IL phase. In these reactive systems, $\mathrm{scCO}_{2}$ has been successfully used to extract products from ILs. The usage of an organic solvent was undesirable, so products and reactants were obtained from the $\mathrm{scCO}_{2}$ phase by depressurization. ${ }^{60,71-75}$ An elegant example of the capabilities of reaction/separation coupling using a $\mathrm{scCO}_{2} / \mathrm{IL}$ biphasic system has been illustrated by Damen et al. ${ }^{76}$ in the design of a 20 ton/year process for the production of Levodopa (a drug used against Parkinson disease). This process has been patented by the same research group. ${ }^{77}$ Huge improvements concerning energy consumption, replacement of deactivated catalyst, solvent replacement, and other variable costs compared to the conventional Monsanto process have been observed, concluding that this biphasic system is rentable at short term ( 1.6 years) despite high investments costs. A review about $\mathrm{scCO}_{2} / \mathrm{IL}$ biphasic systems and their use in homogeneous catalysis has been recently published by Jutz et al.; interested readers are encouraged to consult it. $^{78}$

In another study, the $\mathrm{scCO}_{2}$ phase has been used as a reservoir for substrate and products in a $\mathrm{scCO}_{2} /$ poly (ethylene glycol) (PEG) biphasic system for the selective oxidation of alcohols to aldehydes and ketones performed in the PEG phase. PEG has effectively stabilized the Pd nanoparticles used as catalysts avoiding their agglomeration, and a continuous process has successfully been exemplified by coupling the reaction and separation steps. ${ }^{79,80}$ The same strategy was employed for the oxidation of styrene catalyzed by $\mathrm{PdCl}_{2} /$ $\mathrm{CuCl}$. Usage of PEG as the reactive phase allowed recovering the catalyst without loss in a continuous operation process. ${ }^{81}$

An example of the interesting capabilities of the $\mathrm{scCO}_{2} /$ water biphasic system to allow products/catalyst separations has been shown in the patent by V. S. Bhise, ${ }^{82}$ where ethylene glycol was prepared using a process in which ethylene oxide was extracted from an aqueous solution with near-critical or supercritical carbon dioxide. An ethylene oxide $/ \mathrm{CO}_{2} /$ water mixture was then contacted with a catalyst to form ethylene carbonate, which was then hydrolyzed to ethylene glycol in the presence of the same catalyst. The ethylene glycol was separated as product, and the carbon dioxide and the catalyst were recycled.

Concerning the utilization of GXLs for process intensification, Xie et al. ${ }^{83}$ have published a recent interesting example concerning the utilization of a nanofiltration membrane reactor for a continuous hydroformylation reaction of 1-octene in CXLs. The polyimide membrane allowed the retention of the catalyst inside the reactor without pressure loss.

\section{TUNING OF PHYSICO-CHEMICAL PROPERTIES}

Traditionally, in an industrial manufacturing plant, a solvent recovery step is used after each conversion stage, as the usage of a specific solvent for each reaction step is often necessary. This approach generates wastes and large energy consumption. The development of cascade catalytic reactions in the same solvent and without intermediate recovery steps is considered as an important direction for developing sustainable organic synthesis and chemical processes in the future. ${ }^{84}$ In this scope, the finetuning of reaction conditions, including solvent properties, is a challenge that $\mathrm{scCO}_{2} /$ green solvent biphasic systems can help to overcome. Actually, in these kind of systems, the properties of the "solvent" phase can be finely tuned by controlling the concentration of $\mathrm{CO}_{2}$ that is solubilized in the solvent, which means that by changing the pressure of the system a new phase is obtained with tunable properties that can go from those of the neat solvent to those of pure $\mathrm{CO}_{2}$ in a reversible fashion. Dramatic changes in the properties of certain switchable materials and/or solvents can be triggered by $\mathrm{CO}_{2}$ as this solvent has the advantage of being readily separable by depressurization, which gives knobs to adjust properties of solvents, surfactants, particles, polymers, catalysts, etc. ${ }^{85}$ Even if solvent properties tuning for unique solvent utilization through the entire chemical process has not been developed yet, we give some examples of the usage of properties tuning by $\mathrm{scCO}_{2}$ in biphasic $\mathrm{scCO}_{2}$ /green solvents systems.

\section{MELTING POINT DEPRESSION OF IONIC LIQUIDS}

One interesting feature of the association of $\mathrm{scCO}_{2}$ and ILs is the melting point depression of ionic liquids by $\mathrm{scCO}_{2}$. As has been demonstrated by Leitner et al., ${ }^{84}$ pronounced depressions in the melting point can be induced by compressed $\mathrm{CO}_{2}$ with values even exceeding $100{ }^{\circ} \mathrm{C}$ in some ILs presenting ammonium or phosphonium cation. In the case of $\left[\mathrm{Bu}_{4} \mathrm{~N}\right]$ $\left[\mathrm{BF}_{4}\right]$ a depression of $120{ }^{\circ} \mathrm{C}$ has been observed when pressurized with 150 bar of $\mathrm{CO}_{2}$. These authors have suggested that this behavior results from weak Lewis acid-Lewis base interactions of the acidic carbon of $\mathrm{CO}_{2}$ with the basic moieties of the ILs. This interesting characteristic makes these systems 
suitable for ILs recovery and recycling and may render available some ILs that are not yet used as solvents because of their high melting points.

\section{RHEOLOGICAL PROPERTIES OF POLYMERIC PRODUCTS}

Tunability of properties by $\mathrm{scCO}_{2}$ in a $\mathrm{scCO}_{2} /$ green solvent system can be used not only to change solvent properties but products properties as well, as shown by Quadir et al. ${ }^{86}$ for the emulsion polymerization of methyl methacrylate in a $\mathrm{scCO}_{2} /$ water biphasic system. The plasticizing properties of $\mathrm{CO}_{2}$ have been used to reduce the glass transition temperature, melting temperature, and viscosity of the polymer. Figure 4 shows SEM
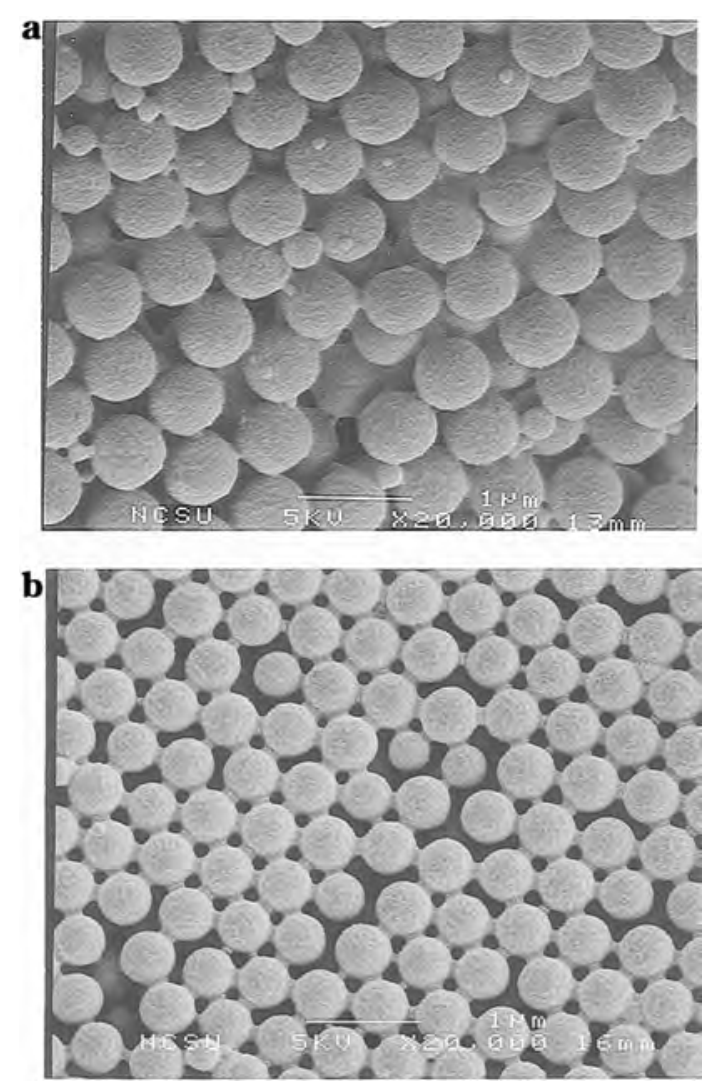

Figure 4. Scanning electron micrographs for particles formed (a) without $\mathrm{CO}_{2}$ and (b) with $\mathrm{CO}_{2}$ at 113 bar. Both samples are taken at about $80 \%$ of conversion. Reprinted with permission from Quadir, M. A; Snook, R.; Gilbert, R. G.; DeSimone, J. M. Macromolecules 1997, 30 (20), 6015-6023. Copyright 1997, American Chemical Society.

micrographs of particles obtained with and without $\mathrm{CO}_{2}$. It can be observed that the spheres obtained without $\mathrm{CO}_{2}$ show a significant population of small particles; mass distribution showed a decrease with $\mathrm{CO}_{2}$ pressure attributed to changes in the chain-stopped mechanism due to a viscosity decrease, which increased the rate of bimolecular termination.

Engineering and Technological Aspects for Implementation of $\mathrm{scCO}_{2} / \mathrm{Green}$ Solvent Systems. Even if $\mathrm{scCO}_{2} /$ green solvent biphasic systems have received great interest in recent years, technologies and apparatus for in situ analytical techniques allowing for the study of these systems are still developing. Also, technological devices improving the contact between both phases and allowing for practical implementation of the operation of biphasic systems both in batch or in continuous mode present enormous opportunities to be explored. As well, process equipment allowing for coupling of separation and reaction steps using such systems can still be thoroughly developed.

As has already been stated, the advantages of such technology include energy economy by reaction/separation coupling, utilization of milder reaction/separation conditions, process safety enhancement by utilization of greener solvents, elimination of flammable vapor phases, and waste mitigation by elimination of organic solvents; all of these features justifies the development of a new generation of equipment and/or techniques allowing us to take advantage of all the potentialities of these systems. In fact, development of such technologies requires understanding of molecular interactions and advanced knowledge of hydrodynamics and mass and heat transfer in complex multiphasic systems. ${ }^{87} \mathrm{We}$ present here some technological and research requirements that in our opinion are needed to implement $\mathrm{scCO}_{2}$ /green solvent biphasic systems and to exploit entirely the capabilities of such systems.

\section{ACQUISITION OF EXPERIMENTAL DATA}

Phase Equilibrium. In order to gain understanding of the factors that affect chemical processes, the study of phase equilibrium between fluids is of fundamental importance. Knowledge of the phase behavior of a reaction system can help understanding and improve the performance of the system, permitting as well the rational design of the entire process. ${ }^{88}$ Phase equilibrium studies of $\mathrm{scCO}_{2} /$ green solvent biphasic systems is crucial when these systems are used for a reaction because this equilibrium plays a role in the partition of reactants, products, and catalysts. As the reaction proceeds, this equilibrium is modified with the disappearance of reactants and the appearance of products, as in the example in Figure 5.

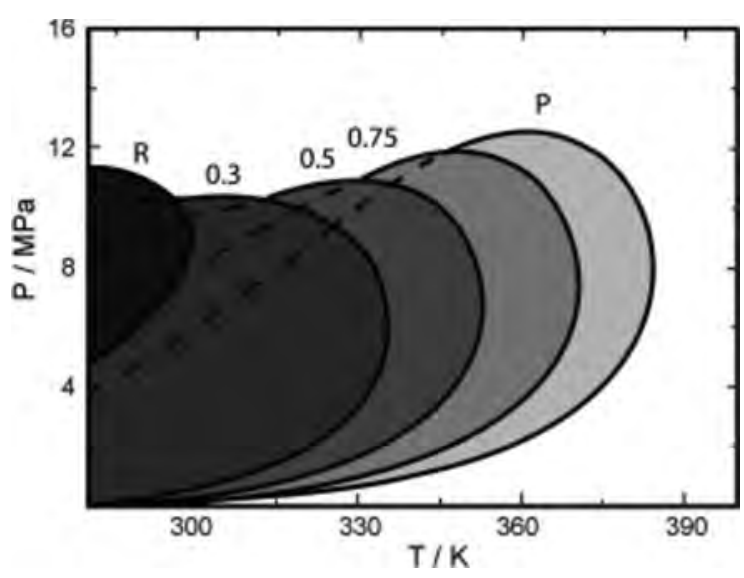

Figure 5. Hydroformylation of propene: progress of the two-phase boundary for a six-component reaction mixture, as the reaction proceeds through different conversions: $\mathrm{R}$ (reactants), 0.3, 0.5, 0.75, and $\mathrm{P}$ (products), indicated in the figure, as calculated by Ke et al. ${ }^{90}$ Reprinted with permission from Nunes da Ponte, M. J. Supercrit. Fluids, 2009, 47 (3), 344-350. Copyright 2009, Elsevier.

Understanding phase equilibrium and its impact in a chemical process allows for controlling the thermodynamic properties of the system in order to influence reaction kinetics and selectivity and also to design separation steps by using a strategy called "phase equilibrium engineering". 89 This idea has been demonstrated by the pressure tuning of the selectivity in the hydrogenation of limonene in a biphasic $\mathrm{CO}_{2} /$ limonene 
system. Actually, hydrogenation of limonene can yield different products, and by controlling the partition of reactants in the liquid phase, the selectivity of the hydrogenation was optimized. $^{44}$

On the other hand, systems formed by $\mathrm{scCO}_{2}$ and ionic liquids have been thoroughly studied and found to form biphasic systems over a large range of pressures and temperatures. These studies have shown that $\mathrm{CO}_{2}$ is highly soluble in some ILs such as [BMIM][PF6] (up to 0.6 of mole fraction at $8 \mathrm{MPa}$ ), while the composition of the $\mathrm{scCO}_{2}$ phase remains essentially $\mathrm{CO}_{2} \cdot{ }^{91}$ The study of the phase behavior of the ternary system $\mathrm{scCO}_{2} /[\mathrm{BMIM}]\left[\mathrm{PF}_{6}\right] /$ naphthalene has shown that it is possible to quantitatively extract naphthalene, a nonvolatile compound by $\mathrm{scCO}_{2}$, from an IL without contamination; pure ionic liquid has been obtained after the depressurization step. ${ }^{91}$

Using the same ionic liquid, Blanchard and Brennecke performed solubility measurements of several polar and nonpolar substrates including alcohols, amides, and ketones, allowing for their recovery by extraction with $\mathrm{scCO}_{2}$ with a recovery of more than $95 \%{ }^{92}$ a correlation has been observed between the amount of $\mathrm{CO}_{2}$ needed for $95 \%$ extraction of the solute and its dipolar moment, which can be explained by the affinity of the solute for $\mathrm{CO}_{2}$. Phase equilibrium of $n$-alkyl-3methyl-imidazolium bis(trifluoromethylsulfonyl)amide ionic liquids with $\mathrm{CO}_{2}$ has been measured by Ren et al., ${ }^{93}$ and the PR EoS with the van der Waals 2-parameter mixing rule with estimated IL critical properties has been used for modeling the experimental results. Good agreement has been obtained between experiments and modeling; however, extrapolation of the model to pressures higher than $40 \mathrm{MPa}$ predicted a critical point of the mixture that has not been observed experimentally.

In order to investigate dimethyl carbonate synthesis using methanol and $\mathrm{scCO}_{2}$, the thermodynamic behavior of a mixture containing reactants and products for this reaction, methanol, $\mathrm{CO}_{2}$, dimethyl carbonate, and water, was studied by the SRK equation of state with MHV2 mixing rules. Binary interaction parameters were deduced from the fitting of experimental data performed in a high-pressure view cell, and good agreement has been found. This study clearly showed the possibility to predict and to choose the right operating conditions for a chemical process from phase equilibrium analysis. ${ }^{94}$

Some studies of the high-pressure phase behavior of biphasic $\mathrm{scCO}_{2}$ /green biosourced solvents have been recently published, such as the systems including $\mathrm{scCO}_{2}$ and methyl lactate, ethyl lactate, ${ }^{95}$ methyl stearate, methyl palmitate, methyl myristate, ${ }^{96}$ and $\mathrm{scCO}_{2} /$ glycerol. ${ }^{97}$ Phase equilibrium of mixtures of $\mathrm{scCO}_{2}$ with fatty acid ethyl esters from fish oil, ${ }^{98}$ soybean oil, and castor oil ${ }^{99}$ were determined in a temperature range from 40 to $70{ }^{\circ} \mathrm{C}$ and pressures up to $30 \mathrm{MPa}$. Other studies concerning phase equilibrium of $\mathrm{scCO}_{2}$ /green solvents such as acetates, propylene carbonate, lactates, soybean oil, squalane, and water have been described in the literature. ${ }^{95,100-106}$ All of these studies give a good insight to the potential systems that can be used for reaction/extraction coupling. High-pressure view cells have been used to perform most of the phase equilibrium experiments, while the system concerning glycerol was studied by using a high-pressure cell coupled to FT-IR. ${ }^{97}$ These studies include modeling results performed by equations of state showing a good correlation between experimental and numerical results. In situ attenuated total reflection infrared spectroscopy was used to investigate the behavior of some $\mathrm{scCO}_{2} / \mathrm{IL}$ systems in the presence and absence of water. It has been observed in this study that the addition of water to the system did not change the $\mathrm{CO}_{2}$ solubility in ILs and that water can be extracted from ILs by $\mathrm{CO}_{2}$, allowing for the drying of the ionic liquids investigated. ${ }^{107}$

Molecular simulation is now an alternative powerful tool for experimental measurements for estimating properties of fluids and materials including phase equilibrium. ${ }^{108}$ Houndonougbo et al. ${ }^{109,110}$ have used molecular simulations and in particular the Gibbs ensemble Monte Carlo (GEMC) method to predict the vapor-liquid equilibrium of systems including $\mathrm{CO}_{2}$ and other solvents such as acetic acid; these results were compared to experimental data. It has been shown that the prediction of volume expansion of solvents in the presence of pressurized $\mathrm{CO}_{2}$ by molecular simulation is excellent. Vapor-liquid equilibria data obtained from these simulations have been used subsequently in the Peng-Robinson equation of state (PR EoS) for systems where experimental data for the mixing parameters lacked, allowing good correlation of the experimental results by PR EoS.

In an effort to develop tools to diminish the quantity of tedious experiments and determinations and to effectively design catalytic biphasic reactions, a mathematical model was developed to predict the thermodynamic equilibrium conversion and yield for biphasic-catalyzed reactions. ${ }^{111}$ This model can be used to predict a suitable solvent combination and to maximize the equilibrium conversion by knowing the equilibrium constant and the partition coefficients for all the reactants in the biphasic medium. In other words, the objective of this study was to answer the question: which solvent combination and which proportion is the most adequate to reach high equilibrium conversions and yields? The model was validated for the alcohol dehydrogenase-catalyzed reduction of acetophenone and verified for eight different biphasic reaction mixtures. Even if this study did not included $\mathrm{scCO}_{2}$ /green solvent biphasic mixtures, a similar concept could be developed for such systems.

\section{OTHER PROMISING GREEN SOLVENTS}

Special kinds of compounds have attracted our attention as very promising for $\mathrm{scCO}_{2}$ /green solvent biphasic systems development. These are biomass derived ILs and deep eutectic solvents (DES). DES are mixtures of compounds that have lower melting points than those of any of their individual components. In particular, when the compounds that constitute the DES are primary metabolites, namely, amino acids, organic acids, sugars, or choline derivatives, they are called natural deep eutectic solvents (NADES). ${ }^{112}$ These biomass-derived ILs and NADES possess well-characterized biodegradable and toxicological properties. For example, fructose-based ILs have been used for the Heck reaction of aryl iodides, exhibiting similar solvent properties than conventional imidazole-based ILs for transition metal-catalyzed reactions. ${ }^{113}$ ILs containing cholinebased cations combined with propionate, tiglate, hydrogen succinate, hydrogen maleate, ${ }^{114}$ and linear alkanoate anions ${ }^{115}$ have been obtained; their biodegradability has already been tested giving satisfactory results. Choline-based cations have been prepared in combination with amino acids as anions such as glycine, alanine, phenylananine, histidine, etc.; their characterization and use in the Knoevenagel condensation under solvent-free conditions between benzaldehyde and different methylene compounds are well documented. ${ }^{116}$ Choline chloride-glycerol DES have been prepared, and their physical properties thoroughly characterized. The solubility of 
gases such as $\mathrm{SO}_{2}{ }^{117}$ and $\mathrm{CO}_{2}$ in these compounds have been measured as well. Saccharin and acesulfame have been employed in the preparation of ILs; anions of both sweeteners (saccharinate and acesulfamate) were combined with onium cations to give salts melting below $100{ }^{\circ} \mathrm{C}$. Even though these anions are not biobased and are prepared from artificial compounds, they are presented here as both of them have interesting toxicological profiles. ${ }^{118}$ Other cations that have been prepared from biosourced resources and used in ILs and DES are ephedrinium salts, nicotinium salts, some compounds obtained from menthol, citronellol, pinene, fructose, urea, and natural polyalcohols such as sorbitol. On the anion side, we can cite camphor-based ILs.

Solubility of $\mathrm{CO}_{2}$ in DES composed of choline chloride and glycerol at moderate pressures has been studied and was found to be similar to solubility of $\mathrm{CO}_{2}$ in typical ILs. Experimental results were compared with modeling by an extended Henry's law model, and good agreement was found.

Liu et al. ${ }^{119}$ have reported the production of 5hydroxymethylfurfural (HMF) from a fructose solution in a $\mathrm{scCO}_{2} /$ choline chloride biphasic system; this system allowed a yield in $\mathrm{HMF}$ of up to $72 \%$ compared to $60 \%$ obtained with the conventional method. Furthermore, $\mathrm{CO}_{2}$ was shown to induce the formation of carbonic acid, which increased the reaction rate. After the reaction, separation of HMF from catalyst was straightforward by depressurizing the system to obtain the product without acid contamination, which cannot be performed by using conventional methods without $\mathrm{CO}_{2}$. Systems containing $\mathrm{scCO}_{2}$ and biosourced DES and ILs hold many promises for the development of innovative processes, and we strongly believe the usage of such systems will reinforce the green character of both solvents, overcoming the issues of separation of biobased ILs that arise from their low volatility and allowing for the fine-tuning of the properties of these compounds by $\mathrm{CO}_{2}$, while keeping the biodegradability and low toxicity of the system.

Other kinds of green solvents obtained by depolymerization of lignin have been prepared by Azadi et al., ${ }^{120}$ and these solvents contained alkyl-substituted phenolics such as propyl guaiacol and propyl syringol. These solvents could be used in biphasic systems containing $\mathrm{scCO}_{2}$ for applications including biosourced compounds as they present high solubilities for certain substances obtained from biomass. However, their toxicological properties need to be completely elucidated. Alkyl levulinates are molecules of particular interest that have already been used as extraction solvents. Some studies about their cytotoxicity and mutagenicity confirm their potential as green solvents. $^{121}$

Glycerol is a green biosourced solvent that has recently received great attention as a solvent for chemical synthesis. ${ }^{56,122-127}$ Even though it has been already demonstrated that glycerol can be an interesting green solvent for chemical reactions, only one attempt to couple $\mathrm{scCO}_{2}$ with glycerol has been performed for the successful extraction of products after the $\beta, \beta$-diarylation of acrylates. ${ }^{57}$ The phase equilibrium of this biphasic system has been studied as well by in situ FT-IR and modeled by the Peng-Robinson equation of state; ${ }^{97}$ this interesting media deserves to be more deeply explored.

Other unsuspected green biosourced solvents have been used for different applications such as the synthesis of highly monodisperse CdSe nanocrystals in olive oil. This synthesis was performed without a phosphine addition, which represents a green route to nanocrystals fabrication. ${ }^{128}$ Unfortunately, no attempts have been made to couple such nonconventional green solvent with $\mathrm{scCO}_{2}$ as reactional biphasic media.

\section{DEVELOPMENT OF CATALYSTS}

As has already been presented, the development of catalysts capable to work in green solvents such as biosourced solvents is a challenge that has been explored by some research groups. ${ }^{129}$ For example, the group of Jerôme ${ }^{57}$ has developed $\mathrm{Pd}$ nanoparticles stabilized by a sugar-based surfactant derived from biomass and used as a ligand for the coordination of palladium; this catalyst has been used for the $\beta, \beta$-diarylation of acrylates in glycerol. The usage of $\mathrm{scCO}_{2}$ allowed the successful extraction of reaction products from the glycerol phase with minimal contamination of glycerol, while the catalyst is immobilized in the glycerol phase. Catalysts capable to work in $\mathrm{scCO}_{2} /$ water systems have been thoroughly studied in an effort to develop greener chemical processes and reactions; some examples are the reduction of $\mathrm{CO}_{2}$, hydrogenations, and others. ${ }^{130}$ However, even if aqueous biphasic catalysis has been created several decades ago and the development of watersoluble organometallic catalysts has widened the possibilities and increased the number of candidate reactions, the available technologies need to be redesigned to use $\mathrm{scCO}_{2} /$ water as reaction media. In our opinion, the opportunity to create an acid catalyst in situ by dissolving $\mathrm{CO}_{2}$ in water, together with the possibility to eliminate it by depressurization (without the need for basic species for neutralization and subsequent salt disposal), has not been completely explored yet. One recent example is the synthesis of urea derivatives from urea and organic amines. In this study, ammonium bicarbonate (ABic) was simultaneously obtained with high-value mono- and bisubstituted ureas without the use of another catalyst than the acidic species created by $\mathrm{CO}_{2}$ dissolution in $\mathrm{H}_{2} \mathrm{O}^{131}$ Released $\mathrm{NH}_{3}$ has been successfully captured by ABic formation, which allowed pollution reduction. Once more, the importance of phase equilibrium was evidenced in this study, showing that inorganic solids (identified as $\mathrm{ABic}$ by ${ }^{13} \mathrm{C}$ NMR) were preferentially obtained when lower pressure was used, which has been attributed to lesser ammonia release at higher pressures. Other efforts may be addressed for catalyst development allowing the usage of $\mathrm{scCO}_{2}$ /green solvent systems to immobilize the catalyst in one of the phases in order to extract products from the second phase.

As an example of the catalysts development for GXLs utilization, Xie et al. $^{83}$ have demonstrated the usage of phosphite ligands (JanaPhos ligands) bound to a $\mathrm{Rh}$ center facilitating $\mathrm{Rh}$ retention in the reactor by a polyimide membrane. This system has been applied to the hydroformylation of 1-octene in CXLs.

\section{TECHNICAL DEVELOPMENTS}

One of the rare examples of technologies developed to use these kinds of systems is supported ionic liquid phases (SILPs), where the IL and the catalyst are deposited as a thin layer onto a high surface area support, the catalyst being dissolved in the ILs. These SILP have been employed in a fixed-bed reactor for the continuous hydroformylation of 1-octene, using dense $\mathrm{CO}_{2}$ as the mobile phase. ${ }^{132-134}$ Due to the decreased viscosity of ILs in the presence of dense $\mathrm{CO}_{2}$, this system allowed better transport of gases to the catalyst increasing the reaction rates and reducing the loss of catalyst. A similar technology exists in the case of water as supported aqueous-phase catalysts (SAPC) 
(Figure 6) and where the catalytic reaction takes place at the water-organic interface where the organic phase contains the

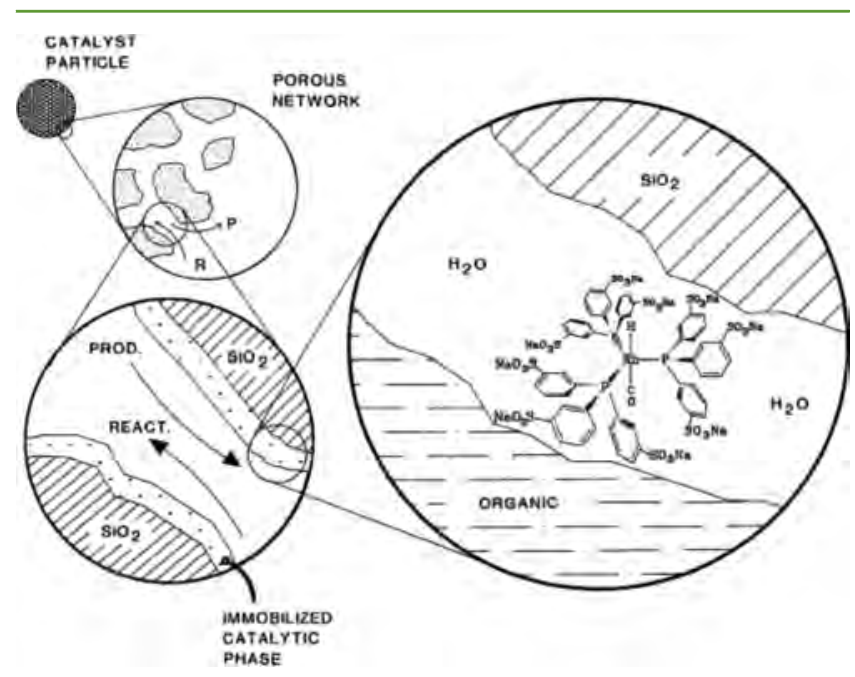

Figure 6. Schematic representation of a SAP catalyst. Reprinted with permission from Arhancet, J. P; et al. ${ }^{136} \mathrm{~J}$. Catal. 1990, 121, 327-339. Copyright 1990, Elsevier.

reactants and products. ${ }^{135136}$ However, SAPC have not been used with dense or supercritical $\mathrm{CO}_{2}$.

The conception and design of new multifunctional technologies ${ }^{87}$ is a field that has barely been developed and would strongly benefit from the versatility of biphasic $\mathrm{scCO}_{2} /$ green solvents systems. New technologies and systems to generate new experimental data permitting or taking into account the usage of tunable green solvents for the coupling of reaction and separation steps by $\mathrm{scCO}_{2}$ need to be developed. In this context, microdevices offer a great opportunity in research and development, as they allow the control of droplets, jets, and in situ characterization and modeling. ${ }^{137}$ These concepts have been very recently studied for the $\mathrm{scCO}_{2} /$ water biphasic system. ${ }^{138}$ In this study, a numerical model to describe the jets and drops generated by $\mathrm{CO}_{2}$ in water at high pressures and high Reynolds numbers in a microdevice has been proposed; changes in wettability and surface tension between both phases originated by the addition of surfactants have been taken into account as well. Calculations and experimental results have been compared, and good agreement has been observed between them.

An electrodispersion contactor has been used to disperse water droplets in $\mathrm{scCO}_{2}$ and was tested in the extraction of ethanol from an aqueous solution in order to increase mass transfer and to broaden the separation and reaction processes capable to be applied to $\mathrm{scCO}_{2}$ usage. ${ }^{139}$ Hollow fiber membrane contactors have been used to allow the contact between $\mathrm{scCO}_{2}$ and water in order to extract solutes of very different partition coefficients such as caffeine, DMF, ethanol, acetone, and ethyl acetate from aqueous solutions. ${ }^{140-144}$ It is worth noting that the operation of hollow fiber contactors at high pressure requires overcoming the delicate challenge of operating at lower transmembrane pressures than the breakthrough pressures of the membranes.

\section{CONCLUSIONS}

Perspectives of $\mathrm{scCO}_{2}$ /green solvent biphasic systems are presented in order to give the reader a good insight into their usages and potential applications. As this perspective paper reflects, $\mathrm{scCO}_{2} /$ green solvent biphasic systems present interesting characteristics that make them useful in green sustainable chemistry and engineering such as mass and energy efficiencies, along with minimization of wastes and safety enhancement. They are also versatility and have modularity. Such systems have been used in a wide variety of reactions like hydroformylations, hydrogenations, oxidations, and so on, where the interesting properties of these systems have been used to solve solubility issues, to couple reaction/separation steps, and to achieve the tuning of properties of the solvents associated with $\mathrm{scCO}_{2}$.

Finally, we have presented some perspectives in the field of green solvents preparation and/or characterization. The aim of presenting these solvents here is to attract the attention toward a possible utilization of these solvents in systems containing $\mathrm{scCO}_{2}$, which allow for overcoming usage issues such as problems with separations and will permit the development of greener processes.

However, we have observed only a few technologies allowing and/or improving the contact between both phases permitting taking advantage of all the properties of these systems even though encouraging developments are already occurring in the laboratories of several research groups. Great opportunities in these fields are open, and we strongly believe that a large development of a new generation of versatile and clean reactor/ separator units for the usage of these promising systems will certainly allow the creation of a new generation of clean intensified processes.

\section{AUTHOR INFORMATION}

\section{Corresponding Author}

*E-mail: yaocihuatl.medinagonzalez@ensiacet.fr.

\section{Notes}

The authors declare no competing financial interest.

\section{Biographies}

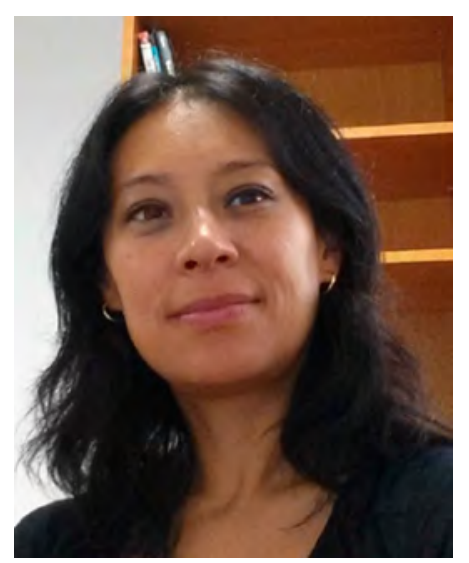

Yaocihuatl Medina-Gonzalez obtained her Chem. Eng. and M.Sc. degrees at the Universidad National Autonoma (UNAM) at Mexico. She obtained a Ph.D. degree at The Institut National Polytechnique de Toulouse in 2003 and then worked as a postdoctoral fellow in the Chemical Engineering Laboratory of Toulouse University and at the University of Western Ontario (Charpentier's group, Clean solvents and Advanced Materials Laboratory). Her research activities have been centered on the utilization of green solvents in process engineering. She is currently a CNRS Associate Scientist at the Chemical Engineering Laboratory at Toulouse, France. 


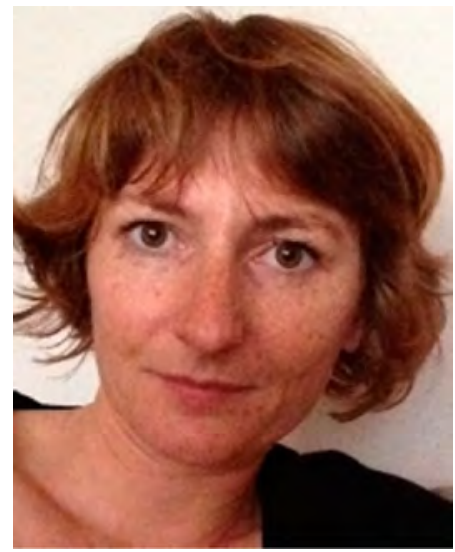

Séverine Camy obtained Chem. Eng. and M.Sc. degrees at the Institut National Polytechnique at Toulouse (INP), France. She then obtained a Ph.D. degree from this intitution in 2000 under the supervision of Pr. Condoret. She is currently an Associate Professor at the INP. Her research topic concerns supercritical fluids (mainly $\mathrm{scCO}_{2}$ ) extraction and reaction processes.

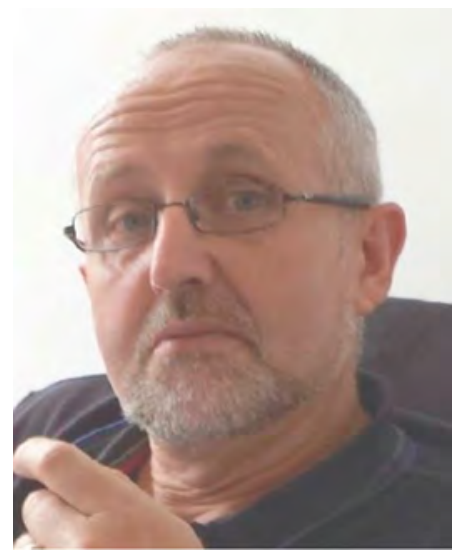

Pr. Jean-Stéphane Condoret is a full professor of chemical engineering at the Ecole Nationale Supérieure en Arts Chimiques et Technologiques, INP-ENSIACET in Toulouse. At the Chemical Engineering Laboratory in Toulouse, France, his research is devoted to development of processes using supercritical fluids. He has published over 60 papers in internationally recognized scientific journals.

\section{REFERENCES}

(1) Zhang, Y.; Bakshi, B. R.; Demessie, E. S. Life cycle assessment of an ionic liquid versus molecular solvents and their applications. Environ. Sci. Technol. 2008, 42, 1724-1730.

(2) Jessop, P. G. Searching for green solvents. Green Chem. 2011, 13, 1391-1398.

(3) Pollet, P.; Davey, E. A.; Urena-Benavides, E. E.; Eckert, C. A.; Liotta, C. L. Solvents for sustainable chemical processes. Green Chem. 2014, 16, 1034-1055.

(4) Vanderveen, J. R.; Durelle, J.; Jessop, P. G. Design and evaluation of switchable-hydrophilicity Solvents. Green Chem. 2014, 16, 11871197.

(5) DeSimone, J. M. Practical approaches to green solvents. Science 2002, 297, 799-803.

(6) Leitner, W.; Poliakof, M. Supercritical fluids in green chemistry. Green Chem. 2008, 10, 730.

(7) Statistics: $\mathrm{CO}_{2}$ Emissions from Fuel Combustion; International Energy Agency: Paris, 2012.

(8) Aresta, M.; Dibenedetto, A. Utilisation of $\mathrm{CO}_{2}$ as a chemical feedstock: Opportunities and challenges. Dalt. Trans. 2007, 29752992.
(9) Díaz-Reinoso, B.; Moure, A.; Domínguez, H.; Parajó, J. C. Supercritical $\mathrm{CO}_{2}$ extraction and purification of compounds with antioxidant activity. J. Agric. Food Chem. 2006, 54, 2441-2469.

(10) Capuzzo, A.; Maffei, M. E.; Occhipinti, A. Supercritical fluid extraction of plant flavors and fragrances. Molecules 2013, 18, 71947238.

(11) Kraujalis, P.; Venskutonis, P. R. Supercritical carbon dioxide extraction of squalene and tocopherols from amaranth and assessment of extracts antioxidant activity. J. Supercrit. Fluids 2013, 80, 78-85.

(12) Sanchez-Vicente, Y.; Cabanas, A.; Renuncio, J. A. R.; Pando, C. Supercritical $\mathrm{CO}_{2}$ as a green solvent for eucalyptus and citrus essential oils processing: Role of thermal effects upon mixing. RSC $A d v$. 2013, 3, 6065-6075.

(13) Herzi, N.; Bouajila, J.; Camy, S.; Cazaux, S.; Romdhane, M.; Condoret, J. S. Comparison between supercritical $\mathrm{CO}_{2}$ extraction and hydrodistillation for two species of eucalyptus: Yield, chemical composition, and antioxidant activity. J. Food Sci. 2013, 78, C667C672.

(14) Machmudah, S.; Kitada, K.; Sasaki, M.; Goto, M.; Munemasa, J.; Yamagata, M. Simultaneous extraction and separation process for coffee beans with supercritical $\mathrm{CO}_{2}$ and water. Ind. Eng. Chem. Res. 2011, 50, 2227-2235.

(15) Camy, S.; Montanari, S.; Rattaz, A.; Vignon, M.; Condoret, J.-S. Oxidation of cellulose in pressurized carbon dioxide. J. Supercrit. Fluids 2009, 51, 188-196.

(16) Condoret, J.-S.; Suzelei, M.; Daniel, S.; Michel, V. Method for the Controlled Oxidation of Polysaccharides. Patent WO2006018552A1, 2004.

(17) Campestrini, S.; Tonellato, U. Selective catalytic oxidations in supercritical carbon dioxide. Curr. Org. Chem. 2005, 9, 31-47.

(18) Yu, C.-C.; Tan, C.-S. Production of para-cymene from alkylation of toluene with propylene in supercritical $\mathrm{CO}_{2}$ over shape-selective HZSM-5 pellets. Ind. Eng. Chem. Res. 2007, 46, 4421-4425.

(19) Walsh, B.; Hyde, J. R.; Licence, P.; Poliakoff, M. The automation of continuous reactions in supercritical $\mathrm{CO}_{2}$ : The acidcatalysed etherification of short chain alcohols. Green Chem. 2005, 7, $456-463$.

(20) Ren, W.; Rutz, B.; Scurto, A. M. High-pressure phase equilibrium for the hydroformylation of 1-octene to nonanal in compressed $\mathrm{CO}_{2}$. J. Supercrit. Fluids 2009, 51, 142-147.

(21) Wesselbaum, S.; Hintermair, U.; Leitner, W. Continuous-flow hydrogenation of carbon dioxide to pure formic acid using an integrated $\mathrm{scCO}_{2}$ process with immobilized catalyst and base. Angew. Chemie Int. Ed. 2012, 51, 8585-8588.

(22) Licence, P.; Ke, J.; Sokolova, M.; Ross, S. K.; Poliakoff, M. Chemical reactions in supercritical carbon dioxide: From laboratory to commercial plant. Green Chem. 2003, 5, 99-104.

(23) Subramaniam, B. Gas-expanded liquids for sustainable catalysis and novel materials: Recent advances. Coord. Chem. Rev. 2010, 254, 1843-1853.

(24) Akien, G. R.; Poliakoff, M. A critical look at reactions in class I and II gas-expanded liquids using $\mathrm{CO}_{2}$ and other gases. Green Chem. 2009, 11, 1083-1100.

(25) Subramaniam, B. Exploiting neoteric solvents for sustainable catalysis and reaction engineering: Opportunities and challenges. Ind. Eng. Chem. Res. 2010, 49, 10218-10229.

(26) Jessop, P. G.; Subramaniam, B. Gas-expanded liquids. Chem. Rev. 2007, 107, 2666-2694.

(27) Chamblee, T. S.; Weikel, R. R.; Nolen, S. A.; Liotta, C. L.; Eckert, C. A. Reversible in situ acid formation for $\beta$-pinene hydrolysis using $\mathrm{CO}_{2}$ expanded liquid and hot water. Green Chem. 2004, 6, 382386.

(28) Musie, G.; Wei, M.; Subramaniam, B.; Busch, D. H. Catalytic oxidations in carbon dioxide-based reaction media, including novel $\mathrm{CO}_{2}$-expanded phases. Coord. Chem. Rev. 2001, 219-221, 789-820.

(29) Wei, M.; Musie, G. T.; Busch, D. H.; Subramaniam, B. $\mathrm{CO}_{2}-$ expanded solvents: Unique and versatile media for performing homogeneous catalytic oxidations. J. Am. Chem. Soc. 2002, 124, $2513-2517$ 
(30) Jessop, P. G.; Olmstead, M. M.; Ablan, C. D.; Grabenauer, M.; Sheppard, D.; Eckert, C. A.; Liotta, C. L. Carbon dioxide as a solubility "switch" for the reversible dissolution of highly fluorinated complexes and reagents in organic solvents: Application to crystallization. Inorg. Chem. 2002, 41, 3463-3468.

(31) Sih, R.; Dehghani, F.; Foster, N. R. Viscosity measurements on gas expanded liquid systems-Methanol and carbon dioxide. J. Supercrit. Fluids 2007, 41, 148-157.

(32) Kelkar, M. S.; Maginn, E. J. Effect of temperature and water content on the shear viscosity of the ionic liquid 1-ethyl-3methylimidazolium bis(trifluoromethanesulfonyl)imide as studied by atomistic simulations. J. Phys. Chem. B 2007, 111, 4867-4876.

(33) Ahosseini, A.; Ortega, E.; Sensenich, B.; Scurto, A. M. Viscosity of $\mathrm{N}$-alkyl-3-methyl-imidazolium bis(trifluoromethylsulfonyl)amide ionic liquids saturated with compressed $\mathrm{CO}_{2}$. Fluid Phase Equilib. 2009, 286, 72-78.

(34) Eckert, C. A.; Bush, D.; Brown, J. S.; Liotta, C. L. Tuning solvents for sustainable technology. Ind. Eng. Chem. Res. 2000, 39, $4615-4621$.

(35) Subramaniam, B. Gas-expanded liquids for sustainable catalysis and novel materials: Recent advances. Coord. Chem. Rev. 2010, 254, $1843-1853$.

(36) Keim, W. Multiphase catalysis and its potential in catalytic processes: The story of biphasic homogeneous catalysis. Green Chem. 2003, 5, 105-111.

(37) Blaser, H.-U.; Studer, M. Catalysis for fine chemicals: Who needs (will use) new solvents? Green Chem. 2003, 5, 112-117.

(38) Collis, A. E. C.; Horvath, I. T. Heterogenization of homogeneous catalytic systems. Catal. Sci. Technol. 2011, 1, 912-919.

(39) Baker, R. T.; Tumas, W. Toward greener chemistry. Science 1999, 284, 1477-1479.

(40) Clark, J. H.; Tavener, S. J. Alternative solvents: Shades of green. Org. Process Res. Dev. 2006, 11, 149-155.

(41) Gu, Y.; Jerome, F. Bio-based solvents: An emerging generation of fluids for the design of eco-efficient processes in catalysis and organic chemistry. Chem. Soc. Rev. 2013, 42, 9550-9570.

(42) M. Bhanage, B.; Shirai, M.; Arai, M.; Ikushima, Y. Multiphase catalysis using water-soluble metal complexes in supercritical carbon dioxide. Chem. Commun. 1999, 1277-1278.

(43) Chouchi, D.; Gourgouillon, D.; Courel, M.; Vital, J.; Nunes da Ponte, $\mathrm{M}$. The influence of phase behavior on reactions at supercritical conditions: The hydrogenation of a-pinene. Ind. Eng. Chem. Res. 2001, 40, 2551-2554.

(44) Bogel-Lukasik, E.; Fonseca, I.; Bogel-Lukasik, R.; Tarasenko, Y. A.; da Ponte, M. N.; Paiva, A.; Brunner, G. Phase equilibrium-driven selective hydrogenation of limonene in high-pressure carbon dioxide. Green Chem. 2007, 9, 427-430.

(45) Lopez-Castillo, Z. K.; Aki, S. N. V. K.; Stadtherr, M. A.; Brennecke, J. F. Enhanced solubility of hydrogen in $\mathrm{CO}_{2}$-expanded liquids. Ind. Eng. Chem. Res. 2007, 47, 570-576.

(46) Combes, G.; Coen, E.; Dehghani, F.; Foster, N. Dense $\mathrm{CO}_{2}$ expanded methanol solvent system for synthesis of naproxen via enantioselective hydrogenation. J. Supercrit. Fluids 2005, 36, 127-136.

(47) Zuo, X.; Niu, F.; Snavely, K.; Subramaniam, B.; Busch, D. H. Liquid phase oxidation of $\mathrm{p}$-xylene to terephthalic acid at medium-high temperatures: Multiple benefits of $\mathrm{CO}_{2}$-expanded liquids. Green Chem. 2010, 12, 260-267.

(48) Grills, D. C.; Fujita, E. New directions for the photocatalytic reduction of $\mathrm{CO}_{2}$ : Supramolecular, $\mathrm{scCO}_{2}$ or biphasic ionic liquid$\mathrm{scCO}_{2}$ systems. J. Phys. Chem. Lett. 2010, 1, 2709-2718.

(49) Beckman, E. J. Production of $\mathrm{H}_{2} \mathrm{O}_{2}$ in $\mathrm{CO}_{2}$ and its use in the direct synthesis of propylene oxide. Green Chem. 2003, 5, 332-336.

(50) Hancu, D.; Beckman, E. J. Generation of hydrogen peroxide directly from $\mathrm{H}$ and $\mathrm{O}$ Using $\mathrm{CO}$ as the solvent. Green Chem. 2001, 3, $80-86$.

(51) Hâncu, D.; Green, J.; Beckman, E. J. $\mathrm{H}_{2} \mathrm{O}_{2}$ in $\mathrm{CO}_{2} / \mathrm{H}_{2} \mathrm{O}$ biphasic systems: Green synthesis and epoxidation reactions. Ind. Eng. Chem. Res. 2002, 41, 4466-4474.
(52) Nolen, S. A.; Lu, J.; Brown, J. S.; Pollet, P.; Eason, B. C.; Griffith, K. N.; Gläser, R.; Bush, D.; Lamb, D. R.; Liotta, C. L.; Eckert, C. A.; Thiele, G. F.; Bartels, K. A. Olefin epoxidations using supercritical carbon dioxide and hydrogen peroxide without added metallic catalysts or peroxy acids. Ind. Eng. Chem. Res. 2001, 41, 316-323.

(53) Jacobson, G. B.; Ted, Lee C.; Johnston, K. P.; Tumas, W. Enhanced catalyst reactivity and separations using water/carbon dioxide emulsions. J. Am. Chem. Soc. 1999, 121, 11902-11903.

(54) Akiyama, Y.; Meng, X.; Fujita, S.; Chen, Y.-C.; Lu, N.; Cheng, H.; Zhao, F.; Arai, M. Carbon Dioxide pressure induced heterogeneous and homogeneous Heck and Sonogashira coupling reactions using fluorinated palladium complex catalysts. J. Supercrit. Fluids 2009, 51, 209-216.

(55) Eckert, C. A.; Liotta, C. L.; Bush, D.; Brown, J. S.; Hallett, J. P. Sustainable reactions in tunable solvents. J. Phys. Chem. B 2004, 108, 18108-18118.

(56) Karam, A.; Villandier, N.; Delample, M.; Koerkamp, C. K.; Douliez, J.-P.; Granet, R.; Krausz, P.; Barrault, J.; Jérôme, F. Rational design of sugar-based-surfactant combined catalysts for promoting glycerol as a solvent. Chem.-Eur. J. 2008, 14, 10196-10200.

(57) Delample, M.; Villandier, N.; Douliez, J.-P.; Camy, S.; Condoret, J.-S.; Pouilloux, Y.; Barrault, J.; Jerome, F. Glycerol as a cheap, safe and sustainable solvent for the catalytic and regioselective $\beta, \beta$-diarylation of acrylates over palladium nanoparticles. Green Chem. 2010, 12, 804808.

(58) Johnston, K. P.; Harrison, K. L.; Clarke, M. J.; Howdle, S. M.; Heitz, M. P.; Bright, F. V.; Carlier, C.; Randolph, T. W. Water-incarbon dioxide microemulsions: An environment for hydrophiles including proteins. Sci. 1996, 271, 624-626.

(59) Capello, C.; Fischer, U.; Hungerbuhler, K. What is a green solvent? A comprehensive framework for the environmental assessment of solvents. Green Chem. 2007, 9, 927-934.

(60) Bösmann, A.; Franciò, G.; Janssen, E.; Solinas, M.; Leitner, W.; Wasserscheid, P. Activation, tuning, and immobilization of homogeneous catalysts in an ionic liquid/compressed $\mathrm{CO}_{2}$ continuous-flow system. Angew. Chem., Int. Ed. 2001, 40, 2697-2699.

(61) Sheldon, R. A.; Lau, R. M.; Sorgedrager, M. J.; van Rantwijk, F.; Seddon, K. R. Biocatalysis in ionic liquids. Green Chem. 2002, 4, 147151

(62) Lozano, P.; de Diego, T.; Carrié, D.; Vaultier, M.; Iborra, J. L. Continuous green biocatalytic processes using ionic liquids and supercritical carbon dioxide. Chem. Commun. 2002, 692-693.

(63) Reetz, M. T.; Wiesenhofer, W.; Francio, G.; Leitner, W. Biocatalysis in ionic liquids: Batchwise and continuous flow processes using supercritical carbon dioxide as the mobile phase. Chem. Commun. 2002, 992-993.

(64) Cenci, S. M.; Cox, L. R.; Leeke, G. A. Ultrasound-induced $\mathrm{CO}_{2} /$ $\mathrm{H}_{2} \mathrm{O}$ emulsions as a medium for clean product formation and separation: The Barbier reaction as a synthetic example. ACS Sustainable Chem. Eng. 2014, 2, 1280-1288.

(65) McCarthy, M.; Stemmer, H.; Leitner, W. Catalysis in inverted supercritical $\mathrm{CO}_{2}$ /aqueous biphasic media. Green Chem. 2002, 4, 501504.

(66) Burgemeister, K.; Franciò, G.; Gego, V. H.; Greiner, L.; Hugl, H.; Leitner, W. Inverted supercritical carbon dioxide/aqueous biphasic media for rhodium-catalyzed hydrogenation reactions. Chem. - A Eur. J. 2007, 13, 2798-2804.

(67) Burgemeister, K.; Francio, G.; Hugl, H.; Leitner, W. Enantioselective Hydrogenation of Polar Substrates in Inverted Supercritical $\mathrm{CO}_{2}$ /aqueous biphasic media. Chem. Commun. 2005, 6026 $-6028$.

(68) Dzyuba, S. V.; Bartsch, R. A. Recent advances in applications of room-temperature ionic liquid/supercritical $\mathrm{CO}_{2}$ systems. Angew. Chemie Int. Ed. 2003, 42, 148-150.

(69) Mahajani, S. M.; Sharma, M. M.; Sridhar, T. Extractive hydration of n-butene with solid acid catalysts in the liquid phase and under supercritical conditions. Chem. Eng. Sci. 2001, 56, 5625-5633.

(70) Subramaniam, B.; Chaudhari, R. V.; Chaudhari, A. S.; Akien, G. R; Xie, Z. Supercritical fluids and gas-expanded liquids as tunable 
media for multiphase catalytic reactions. Chem. Eng. Sci. 2014, 115, 318.

(71) Gordon, C. M. New developments in catalysis using ionic liquids. Appl. Catal. A Gen. 2001, 222, 101-117.

(72) Brown, R. a; Pollet, P.; McKoon, E.; Eckert, C. a; Liotta, C. L.; Jessop, P. G. Asymmetric hydrogenation and catalyst recycling using ionic liquid and supercritical carbon dioxide. J. Am. Chem. Soc. 2001, 123, 1254-1255.

(73) Liu, F.; Abrams, M. B.; Baker, R. T.; Tumas, W. Phase-separable catalysis using room temperature ionic liquids and supercritical carbon dioxide. Chem. Commun. 2001, 433-434.

(74) Sellin, M. F.; Webb, P. B.; Cole-Hamilton, D. J. Continuous flow homogeneous catalysis: hydroformylation of alkenes in supercritical fluid-ionic liquid biphasic mixtures. Chem. Commun. 2001, 781-782.

(75) Webb, P. B.; Sellin, M. F.; Kunene, T. E.; Williamson, S.; Slawin, A. M. Z.; Cole-Hamilton, D. J. Continuous flow hydroformylation of alkenes in supercritical fluid-ionic liquid biphasic systems. J. Am. Chem. Soc. 2003, 125, 15577-15588.

(76) Damen, M. R.; Brand, R. W.; Bloem, S. C.; Pingen, E.; Steur, K.; Peters, C. J.; Witkamp, G.-J.; Kroon, M. C. Process intensification by combining ionic liquids and supercritical carbon dioxide applied to the design of Levodopa production. Chem. Eng. Process. 2009, 48, 549553.

(77) Kroon, M. C.; Florusse, L. J.; Peters, C. J.; van Spronsen, J.; Witkamp, G.-J.; Sheldon, R. A.; I, G. K. Process for Carrying out a Chemical Reaction with Ionic Liquid and Carbon Dioxide under Pressure. Patent WO2006088348 (A1), 2006.

(78) Jutz, F.; Andanson, J.-M.; Baiker, A. Ionic liquids and dense carbon dioxide: A beneficial biphasic system for catalysis. Chem. Rev. 2011, 111, 322-353.

(79) Hou, Z.; Theyssen, N.; Brinkmann, A.; Leitner, W. Biphasic aerobic oxidation of alcohols catalyzed by poly(ethylene glycol)stabilized palladium nanoparticles in supercritical carbon dioxide. Angew. Chem., Int. Ed. 2005, 44, 1346-1349.

(80) Hou, Z.; Theyssen, N.; Leitner, W. Palladium nanoparticles stabilised on PEG-modified silica as catalysts for the aerobic alcohol oxidation in supercritical carbon dioxide. Green Chem. 2007, 9, 127132.

(81) Wang, J.-Q.; Cai, F.; Wang, E.; He, L.-N. Supercritical carbon dioxide and poly(ethylene glycol): An environmentally benign biphasic solvent system for aerobic oxidation of styrene. Green Chem. 2007, 9, 882-887.

(82) Bhise, V. S. U.S. Patent 4,400,559, 1983.

(83) Xie, Z.; Fang, J.; Subramaniam, B.; Maiti, S. K.; Snavely, W.; Tunge, J. A. Enhanced hydroformylation by carbon dioxide-expanded media with soluble $\mathrm{Rh}$ complexes in nanofiltration membrane reactors. AIChE J. 2013, 59, 4287-4296.

(84) Scurto, A. M.; Leitner, W. Expanding the useful range of ionic liquids: Melting point depression of organic salts with carbon dioxide for biphasic catalytic reactions. Chem. Commun. 2006, 3681-3683.

(85) Jessop, P. G.; Mercer, S. M.; Heldebrant, D. J. $\mathrm{CO}_{2}$-triggered switchable solvents, surfactants, and other materials. Energy Environ. Sci. 2012, 5, 7240-7253.

(86) Quadir, M. A.; Snook, R.; Gilbert, R. G.; DeSimone, J. M. Emulsion polymerization in a hybrid carbon dioxide/aqueous medium. Macromolecules 1997, 30, 6015-6023.

(87) Dudukovic, M. P. Frontiers in reactor engineering. Science 2009, $325,698-701$.

(88) Akien, G. R.; Skilton, R. A.; Poliakoff, M. Pressure drop as a simple method for locating phase transitions in continuous flow high pressure reactors. Ind. Eng. Chem. Res. 2010, 49, 4974-4980.

(89) Brignole, E. A.; Pereda, S.. Eds.; Preface. In Phase Equilibrium Engineering; Supercritical Fluid Science and Technology; Elsevier: Amsterdam, 2013; Vol. 3, pp xiii-xiv.

(90) Ke, J.; Han, B.; George, M. W.; Yan, H.; Poliakoff, M. How does the critical point change during a chemical reaction in supercritical fluids? A study of the hydroformylation of propene in supercritical $\mathrm{CO}_{2}$. J. Am. Chem. Soc. 2001, 123, 3661-3670.
(91) Blanchard, L. A.; Hancu, D.; Beckman, E. J.; Brennecke, J. F. Green processing using ionic liquids and $\mathrm{CO}_{2}$. Nature 1999, 399, $28-$ 29.

(92) Blanchard, L. A.; Brennecke, J. F. Recovery of organic products from ionic liquids using supercritical carbon dioxide. Ind. Eng. Chem. Res. 2000, 40, 287-292.

(93) Ren, W.; Sensenich, B.; Scurto, A. M. High-pressure phase equilibria of \{carbon dioxide $\left(\mathrm{CO}_{2}\right)+\mathrm{N}$-alkyl-imidazoliumbis(trifluoromethylsulfonyl)amide\} ionic liquids. J. Chem. Thermodyn. 2010, 42, 305-311.

(94) Camy, S.; Pic, J.-S.; Badens, E.; Condoret, J.-S. Fluid phase equilibria of the reacting mixture in the dimethyl carbonate synthesis from supercritical $\mathrm{CO}_{2}$. J. Supercrit. Fluids 2003, 25, 19-32.

(95) Cho, D. W.; Shin, M. S.; Shin, J.; Bae, W.; Kim, H. Highpressure phase behavior of methyl lactate and ethyl lactate in supercritical carbon dioxide. J. Chem. Eng. Data 2011, 56, 3561-3566.

(96) Inomata, H.; Kondo, T.; Hirohama, S.; Arai, K.; Suzuki, Y.; Konno, M. Vapour-liquid equilibria for binary mixtures of carbon dioxide and fatty acid methyl esters. Fluid Phase Equilib. 1989, 46, 4152.

(97) Medina-Gonzalez, Y.; Tassaing, T.; Camy, S.; Condoret, J.-S. Phase equilibrium of the $\mathrm{CO}_{2}$ /glycerol system: Experimental data by in situ FT-IR spectroscopy and thermodynamic modeling. J. Supercrit. Fluids 2013, 73, 97-107.

(98) Staby, A.; Forskov, T.; M?llerup, J. Phase equilibria of fish oil fatty acid ethyl esters and sub- and supercritical $\mathrm{CO}_{2}$. Fluid Phase Equilib. 1993, 87, 309-340.

(99) Ndiaye, P. M.; Franceschi, E.; Oliveira, D.; Dariva, C.; Tavares, F. W.; Oliveira, J. V. Phase behavior of soybean oil, castor oil and their fatty acid ethyl esters in carbon dioxide at high pressures. J. Supercrit. Fluids 2006, 37, 29-37.

(100) Cheng, K.-W.; Tang, M.; Chen, Y.-P. Vapor-liquid equilibria of carbon dioxide with diethyl oxalate, ethyl laurate, and dibutyl phthalate binary mixtures at elevated pressures. Fluid Phase Equilib. 2001, 181, 1-16.

(101) Feng, L.-C.; Cheng, K.-W.; Tang, M.; Chen, Y.-P. Vaporliquid equilibria of carbon dioxide with ethyl benzoate, diethyl succinate and isoamyl acetate binary mixtures at elevated pressures. $J$. Supercrit. Fluids 2001, 21, 111-121.

(102) Hwu, W.-H.; Cheng, J.-S.; Cheng, K.-W.; Chen, Y.-P. Vaporliquid equilibrium of carbon dioxide with ethyl caproate, ethyl caprylate and ethyl caprate at elevated pressures. J. Supercrit. Fluids 2004, 28, 1-9.

(103) Hongling, L.; Rongjiao, Z.; Wei, X.; Yanfen, L.; Yongju, S.; Yiling, T. Vapor-liquid equilibrium data of the carbon dioxide + ethyl butyrate and carbon dioxide + propylene carbonate systems at pressures from (1.00 to 13.00) MPa and temperatures from (313.0 to 373.0) K. J. Chem. Eng. Data 2011, 56, 1148-1157.

(104) Tian, Y.-L.; Zhu, H.-G.; Xue, Y.; Liu, Z.-H.; Yin, L. Vaporliquid equilibria of the carbon dioxide + ethyl propanoate and carbon dioxide + ethyl acetate systems at pressure from 2.96 to $11.79 \mathrm{MPa}$ and temperature from 313 to 393 K. J. Chem. Eng. Data 2004, 49, $1554-1559$.

(105) Reverchon, E.; Poletto, M.; Osséo, L. S.; Somma, M. Hexane elimination from soybean oil by continuous packed tower processing with supercritical $\mathrm{CO}_{2}$. J. Am. Oil Chem. Soc. 2000, 77, 9-14.

(106) Sovová, H.; Jez, J.; Khachaturyan, M. Solubility of squalane, dinonyl phthalate and glycerol in supercritical $\mathrm{CO}_{2}$. Fluid Phase Equilib. 1997, 137, 185-191.

(107) Andanson, J.-M.; Jutz, F.; Baiker, A. Investigation of binary and ternary systems of ionic liquids with water and/or supercritical $\mathrm{CO}_{2}$ by in situ attenuated total reflection infrared spectroscopy. J. Phys. Chem. B 2010, 114, 2111-2117.

(108) Panagiotopoulos, A. Z. Monte Carlo methods for phase equilibria of fluids. J. Phys.: Condens. Matter 2000, 12, R25.

(109) Houndonougbo, Y.; Jin, H.; Rajagopalan, B.; Wong, K.; Kuczera, K.; Subramaniam, B.; Laird, B. Phase equilibria in carbon dioxide expanded solvents: Experiments and molecular simulations. J. Phys. Chem. B 2006, 110, 13195-13202. 
(110) Houndonougbo, Y.; Kuczera, K.; Subramaniam, B.; Laird, B. B. Prediction of phase equilibria and transport properties in carbondioxide expanded solvents by molecular simulation. Mol. Simul. 2007, 33, 861-869.

(111) Eckstein, M. F.; Peters, M.; Lembrecht, J.; Spiess, A. C.; Greiner, L. Maximise equilibrium conversion in biphasic catalysed reactions: mathematical description and practical guideline. Adv. Synth. Catal. 2006, 348, 1591-1596.

(112) Paiva, A.; Craveiro, R.; Aroso, I.; Martins, M.; Reis, R. L.; Duarte, A. R. C. Natural deep eutectic solvents - solvents for the 21st century. ACS Sustainable Chem. Eng. 2014, 2, 1063-1071.

(113) Handy, S. T.; Okello, M.; Dickenson, G. Solvents from biorenewable sources: Ionic liquids based on fructose. Org. Lett. 2003, 5, 2513-2515.

(114) Fukaya, Y.; Iizuka, Y.; Sekikawa, K.; Ohno, H. Bio ionic liquids: Room temperature ionic liquids composed wholly of biomaterials. Green Chem. 2007, 9, 1155-1157.

(115) Petkovic, M.; Ferguson, J. L.; Gunaratne, H. Q. N.; Ferreira, R.; Leitao, M. C.; Seddon, K. R.; Rebelo, L. P. N.; Pereira, C. S. Novel biocompatible cholinium-based ionic liquids-toxicity and biodegradability. Green Chem. 2010, 12, 643-649.

(116) Moriel, P.; García-Suárez, E. J.; Martínez, M.; García, a. B.; Montes-Morán, M. a.; Calvino-Casilda, V.; Bañares, M. a. Synthesis, characterization, and catalytic activity of ionic liquids based on biosources. Tetrahedron Lett. 2010, 51, 4877-4881.

(117) Yang, D.; Hou, M.; Ning, H.; Zhang, J.; Ma, J.; Yang, G.; Han, B. Efficient $\mathrm{SO}_{2}$ absorption by renewable choline chloride-glycerol deep eutectic solvents. Green Chem. 2013, 15, 2261.

(118) Lipinski, G. R. Ullman's Encyclopedia of Industrial Chemistry; 2003; p 407.

(119) Liu, F.; Barrault, J.; De Oliveira Vigier, K.; Jérôme, F. Dehydration of highly concentrated solutions of fructose to 5hydroxymethylfurfural in a cheap and sustainable choline chloride/ carbon dioxide system. ChemSusChem 2012, 5, 1223-1226.

(120) Azadi, P.; Carrasquillo-Flores, R.; Pagan-Torres, Y. J.; Gurbuz, E. I.; Farnood, R.; Dumesic, J. A. Catalytic conversion of biomass using solvents derived from lignin. Green Chem. 2012, 14, 1573-1576.

(121) Démolis, A.; Essayem, N.; Rataboul, F. Synthesis and applications of alkyl levulinates. ACS Sustainable Chem. Eng. 2014, 2, $1338-1352$.

(122) He, F.; Li, P.; Gu, Y.; Li, G. Glycerol as a promoting medium for electrophilic activation of aldehydes: Catalyst-free synthesis of di(indolyl)methanes, xanthene-1,8 $(2 \mathrm{H})$-diones and 1-oxo-hexahydroxanthenes. Green Chem. 2009, 11, 1767-1773.

(123) Safaei, H. R.; Shekouhy, M.; Rahmanpur, S.; Shirinfeshan, A. Glycerol as a biodegradable and reusable promoting medium for the catalyst-free one-pot three component synthesis of $4 \mathrm{H}$-pyrans. Green Chem. 2012, 14, 1696-1704.

(124) Wolfson, A.; Dlugy, C.; Shotland, Y. Glycerol as a green solvent for high product yields and selectivities. Environ. Chem. Lett. 2007, 5, 67-71.

(125) Gu, Y.; Barrault, J.; Jérôme, F. Glycerol as an efficient promoting medium for organic reactions. Adv. Synth. Catal. 2008, 350, 2007-2012.

(126) Gu, Y.; Jerome, F. Glycerol as a sustainable solvent for green chemistry. Green Chem. 2010, 12, 1127-1138.

(127) Diaz-Alvarez, A. E.; Francos, J.; Lastra-Barreira, B.; Crochet, P.; Cadierno, V. Glycerol and derived solvents: New sustainable reaction media for organic synthesis. Chem. Commun. 2011, 47, 6208-6227.

(128) Sapra, S.; Rogach, A. L.; Feldmann, J. Phosphine-free synthesis of monodisperse CdSe nanocrystals in olive oil. J. Mater. Chem. 2006, $16,3391-3395$.

(129) Nunes da Ponte, M. Phase equilibrium-controlled chemical reaction kinetics in high pressure carbon dioxide. J. Supercrit. Fluids 2009, 47, 344-350.

(130) Shimizu, K.; Cheng, I. F.; Wang, J. S.; Yen, C. H.; Yoon, B.; Wai, C. M. Water-in-supercritical $\mathrm{CO}_{2}$ microemulsion for synthesis of carbon-nanotube-supported Pt electrocatalyst for the oxygen reduction reaction. Energy Fuels 2008, 22, 2543-2549.
(131) Zhang, R.; Guo, L.; Chen, J.; Gan, H.; Song, B.; Zhu, W.; Hua, L.; Hou, Z. $\mathrm{CO}_{2} /$ water-regulating transamidation of urea and amines. ACS Sustainable Chem. Eng. 2014, 2, 1147-1154.

(132) Hintermair, U.; Gong, Z.; Serbanovic, A.; Muldoon, M. J.; Santini, C. C.; Cole-Hamilton, D. J. Continuous flow hydroformylation using supported ionic liquid phase catalysts with carbon dioxide as a carrier. Dalton Trans. 2010, 39, 8501-8510.

(133) Hintermair, U.; Francio, G.; Leitner, W. Continuous flow organometallic catalysis: New wind in old sails. Chem. Commun. 2011, 47, 3691-3701.

(134) Hintermair, U.; Franciò, G.; Leitner, W. A fully integrated continuous-flow system for asymmetric catalysis: Enantioselective hydrogenation with supported ionic liquid phase catalysts using supercritical $\mathrm{CO}_{2}$ as the mobile phase. Chem. - A Eur. J. 2013, 19, $4538-4547$.

(135) Arhancet, J. P.; Davis, M. E.; Merola, J. S.; Hanson, B. E. Hydroformylation by supported aqueous-phase catalysis: A new class of heterogeneous catalysts. Nature 1989, 339, 454-455.

(136) Arhancet, J. P.; Davis, M. E.; Merola, J. S.; Hanson, B. E. Supported aqueous-phase catalysts. J. Catal. 1990, 121, 327-339.

(137) Marre, S.; Roig, Y.; Aymonier, C. Supercritical microfluidics: Opportunities in flow-through chemistry and materials science. J. Supercrit. Fluids 2012, 66, 251-264.

(138) Guillaument, R.; Erriguible, A.; Aymonier, C.; Marre, S.; SubraPaternault, P. Numerical simulation of dripping and jetting in supercritical fluids/liquid micro coflows. J. Supercrit. Fluids 2013, 81, $15-22$.

(139) Heath, K. D.; Cochran, H. D. Electrodispersion for supercritical $\mathrm{CO}_{2}$-water phase contact. Ind. Eng. Chem. Res. 2000, $39,4455-4461$.

(140) Moreno, T.; Tallon, S. J.; Catchpole, O. J. Supercritical $\mathrm{CO}_{2}$ Extraction of 1-Butanol From Aqueous Solutions Using a Hollow Fibre Membrane Contactor; AIChE Annual Meeting; Pittsburgh, PA, 2012.

(141) Gabelman, A.; Hwang, S.-T. Experimental results versus model predictions for dense gas extraction using a hollow fiber membrane contactor. J. Supercrit. Fluids 2005, 35, 26-39.

(142) Gabelman, A.; Hwang, S.-T.; Krantz, W. B. Dense gas extraction using a hollow fiber membrane contactor: Experimental results versus model predictions. J. Membr. Sci. 2005, 257, 11-36.

(143) Bothun, G. D.; Knutson, B. L.; Strobel, H. J.; Nokes, S. E.; Brignole, E. A.; Díaz, S. Compressed solvents for the extraction of fermentation products within a hollow fiber membrane contactor. $J$. Supercrit. Fluids 2003, 25, 119-134.

(144) Bothun, G. D.; Knutson, B. L.; Strobel, H. J.; Nokes, S. E. Mass transfer in hollow fiber membrane contactor extraction using compressed solvents. J. Membr. Sci. 2003, 227, 183-196. 